\title{
Atomistic Simulation of High-Density Uranium Fuels
}

\author{
Jorge Eduardo Garcés ${ }^{1}$ and Guillermo Bozzolo ${ }^{2}$ \\ ${ }^{1}$ Centro Atómico Bariloche, Comisión Nacional de Energía Atómica, 8400 Bariloche, Argentina \\ ${ }^{2}$ Nuclear Engineering Division, Argonne National Laboratory, 9700 S. Cass Ave., Argonne, IL 60439, USA
}

Correspondence should be addressed to Jorge Eduardo Garcés, garces@cab.cnea.gov.ar

Received 23 July 2010; Accepted 16 November 2010

Academic Editor: Alejandro Clausse

Copyright ( 2011 J. E. Garcés and G. Bozzolo. This is an open access article distributed under the Creative Commons Attribution License, which permits unrestricted use, distribution, and reproduction in any medium, provided the original work is properly cited.

We apply an atomistic modeling approach to deal with interfacial phenomena in high-density uranium fuels. The effects of Si, as additive to $\mathrm{Al}$ or as $\mathrm{U}$-Mo-particles coating, on the behavior of the $\mathrm{Al} / \mathrm{U}$-Mo interface is modeled by using the Bozzolo-FerranteSmith (BFS) method for alloys. The basic experimental features characterizing the real system are identified, via simulations and atom-by-atom analysis. These include (1) the trend indicating formation of interfacial compounds, (2) much reduced diffusion of $\mathrm{Al}$ into U-Mo solid solution due to the high Si concentration, (3) Si depletion in the Al matrix, (4) an unexpected interaction between Mo and Si which inhibits Si diffusion to deeper layers in the U-Mo solid solution, and (5) the minimum amount of Si needed to perform as an effective diffusion barrier. Simulation results related to alternatives to Si dispersed in the $\mathrm{Al}$ matrix, such as the use of $\mathrm{C}$ coating of U-Mo particles or $\mathrm{Zr}$ instead of the $\mathrm{Al}$ matrix, are also shown. Recent experimental results confirmed early theoretical proposals, along the lines of the results reported in this work, showing that atomistic computational modeling could become a valuable tool to aid the experimental work in the development of nuclear fuels.

\section{Introduction}

Multiscale modeling and simulation of materials (MMM) are important areas of research aiming at developing new materials with specific properties. Although the properties of materials at the fundamental level are dictated by the basic laws of quantum mechanics, their prediction through a direct $a b$ initio electronic structure calculation is an ambitious task, even with the current computational resources. These limitations suggest that future material development programs should be implemented based on the synergy between theory, modeling, and experiment, through a continuous and necessary feedback between these usually disconnected areas of research. If the bridge between theory and experiment is not well established, the method for developing or improving specific alloys is reduced to the usual experimental trial and error approach, which is both expensive and time-consuming. However, narrowing the gap between the atomistic methods and experimentation is not a trivial task, and a considerable effort to improve these methods is needed to enhance their predictive power.
In particular, it is now recognized that the research and development of nuclear fuels and cladding materials for advanced reactors could benefit from a well-established theoretical-experimental framework. Although MMM could provide such framework, its current limitations leave atomistic modeling as the only reliable alternative to be applied in real technological problems. As such, the increasing role of atomistic computational modeling in the development of materials in other technological areas has shown promise as a valuable tool to aid the experimental work. In pursuing this goal, it is important to keep in mind that the purpose of atomistic modeling is not to exactly reproduce every detail of the real process but rather to create an idealized, simplified system, where one would be able to identify the main features and driving mechanisms of observed behaviors. If theoretical modeling could also be included in the development of materials and nuclear fuels researchs programs, then the experimental process could probably be better oriented and, as a consequence, the number of experiments could be reduced to specific ones correlated in number and nature to the guidance provided by the theoretical predictions. 
However, the synergy between theory and experiment can not always be achieved, and the following questions arise: how to gain confidence in the theoretical methods in order to implement and develop completely the necessary synergy with an optimum balance between both research areas? How do researchers conclude that a theoretical result is good enough to deserve attention and to include it in the research process?

One major example in recent nuclear research is the development of high-density U-alloys with an increased concentration of $U$ for high neutron flux research reactors with low enrichment uranium (LEU, ${ }^{235} \mathrm{U}<20$ at\%) fuel. Of particular interest is the U-Mo solid solution in the $\gamma$-phase dispersed in an $\mathrm{Al}$ matrix or in a monolithic form, which generated high expectation due to its apparent acceptable irradiation behavior, low to moderate fuel/matrix interaction, and stable fission gas bubble growth for moderate neutron fluxes [1-3]. However, unexpected failures like pillowing and large porosities in LEU U-Mo dispersion plates and tubes in high neutron flux irradiation experiments have been reported [4]. Since these failures were recognized in $2004[5,6]$, much effort has been devoted to the search for their root cause and, mainly, to find a solution. It is now generally accepted that the properties of the interaction layer formed between the UMo fuel kernels and the $\mathrm{Al}$ matrix, which has been proven to become amorphous under irradiation [7-9], are important factors in the failures. To this effect, Gan et al. presented a detailed analysis of the radiation stability of the interaction product formed at the fuel-matrix interface and identified the $\mathrm{U}_{6} \mathrm{Mo}_{4} \mathrm{Al}_{43}$ phase as the problematic one [10]. It is also recognized, based on diffusion couple and in-pile irradiation experiments, that the addition of Si to the Al matrix has a beneficial effect on the interaction layer formation rate and its properties [11-14]. Among others, one current question is how much $\mathrm{Si}$ is required to stabilize the fuel plate behavior in various reactor operating conditions. Although there is no definite consensus on the required quantity, it can be safely concluded from existing experimental results that more than $2 \mathrm{wt} \% \mathrm{Si}$ in the Al matrix is needed [15-17] and probably closer to 4-6 wt\% Si will be required [14]. Current estimates are based on the quantity of Si required to avoid formation of $\mathrm{UAl}_{4}$-type compounds, which have a higher free volume and which, according to the ternary phase diagram, do not form whenever the Si concentration in a U-Al-Si phase is above $5 \mathrm{wt} \%$, neglecting the influence of Mo [18, 19]. Another concern is that as long as $\mathrm{Si}$ as an additive is an option, the added amount should be kept at a minimum in order to improve acceptability by the reprocessing plant.

Although current work on $\mathrm{Al} / \mathrm{U}-\mathrm{Mo}$ fuel is based on experimental research, a theoretical effort aimed to understand the atomic behavior at the interface and help search for a solution was carried out during the development program [20-22]. Those early theoretical results, presented first in a series of meetings held at Constituyentes Atomic Center (CAC), CNEA, Argentina, between 2004-2005 [23-25], gave a detailed description of the main features observed experimentally at that time. The theoretical results clearly indicated that an amount around $5 \mathrm{wt} \% \mathrm{Si}$ is required to avoid deep $\mathrm{Al}$ interdiffusion and to produce a good diffusional barrier for the remaining elements. The theoretical results also showed that the minimum amount of $\mathrm{Si}$ is strongly dependent on the Mo content in the U-Mo solid solution. It is important to remark here that the failure of Si to avoid porosity formation could lead to the need for other alternatives. There is, however, limited available background to make new choices. To aid in this process, computational methods based on sound physical theories might provide an alternative source of information and insight that could benefit the research process more efficiently. A clear example is the theoretical result that proposed the use of $\mathrm{C}$ coating as an alternative to Si to generate a diffusional barrier [25]. Although the results were interesting enough to deserve attention from the experimentalists, the proposal was not considered in the research process which focused, at that time, only on the Si alternative.

The high-density uranium fuel is a clear example of the potential benefit and rapid growth of a research program if a coordinated theoretical-experimental effort is implemented at the beginning of the process. Unfortunately, the theoretical modeling component of the program was limited to the identification of the basic features characterizing the outof-pile diffusion experiments, and many of its useful results did not become an integral part of the research plan. As recent experimental results give new support to these early proposals, it is the purpose of this work to summarize some of them, and provide the basis that motivated these conclusions five years ago.

In this work, therefore, the Bozzolo-Ferrante-Smith (BFS) method for alloys [26, 27] is applied to modeling the interface behavior. It is shown that atomistic computational modeling could become a valuable tool to aid the experimental work in the development of nuclear fuels through the understanding of basic features observed in the $(\mathrm{Al}, \mathrm{Si}) /(\mathrm{U}$, Mo) interface and in the search for alternatives to Si. The paper is organized as follows: Section 2 is devoted to the BFS method for alloys while Section 3 shows the modeling results obtained through atom-by-atom analysis and Monte Carlo simulations performed to further understand the role of $\mathrm{Si}$ in the Al/U-Mo interface. Section 3 also shows the results obtained by applying the same methodology to study the effect of $\mathrm{C}$ coating in U-Mo particles, as well as the use of $\mathrm{Zr}$ as the matrix element. Finally, general conclusions are presented in Section 4.

\section{Theoretical Methodology}

The field of MMM has opened a new era in computational material science for the study of complex phenomena such as the behavior of new fuels and cladding materials. The MMM methodology is based on electronic structure calculations through $a b$ initio codes to study structural, electronic, and elastic properties, followed by the development of interatomic potentials for use in molecular dynamics and kinetic Monte Carlo codes. There is a continuous feedback between methods, and the transfer of information is mediated by properties such as density, free energy, thermal conductivity, and species mobility. Nowadays, the coupling between methods is still imperfect, and it is recognized by the international community that much work is needed in order to produce 
reliable predictions of nuclear fuel and cladding materials behavior in a reactor environment. An alternative to MMM at the beginning of our theoretical research in 2003 was the use of atomistic modeling, based on the combination of the BFS method for the energetics and Monte Carlo methods for the configurational contributions, to help in the search for a solution for the technological problem of high-density fuels.

It is important to note that the tendency to incorporate atomistic simulations as a standard tool in the analysis of complex systems has imposed high expectations on the range of applicability of theoretical approximate methods, their computational efficiency, their ease of implementation, and the type of output that they provide. Almost independently of their foundation and formulation, these methods rely on simplifications which, as a result, inevitably require the introduction of, usually, nontransferable parameters. The BFS method for alloys [26] fulfills several requirements for applicability in terms of simplicity, accuracy, and range of application, as it has no limitations in its formulation on the number and type of elements present in a given alloy. This freedom from fundamental limitations for its applicability is mostly due to the underlying basis of the method. The BFS method introduces simplifications, basically opting for replacing the real process of alloy formation with two virtual processes for the separate evaluation of structural and chemical effects with a minimal set of adjustable parameters expected to reproduce the essential features of the equation of state of the solid at zero temperature and, in particular, around equilibrium. The BFS parameters remain fixed, fully transferable, for any case dealing with the same elements, regardless of their number, type, or structural bulk or surface properties. This universal behavior of the parameters of the BFS method implies a different approach for dealing with the interaction between different atoms. In general, most approaches introduce some sort of interaction potential, with the parameters describing each constituent remaining unchanged in different applications. In BFS, instead of defining interaction potentials, it is precisely the set of parameters describing the pure element that is perturbed in order to account for the distortion in the charge density introduced by the nearby presence of a different element or defect. Moreover, the additive nature of perturbation theory on which the method relies [27] results in that only binary systems need to be known within the BFS framework. Multicomponent systems are thus studied only via binary perturbations: the perturbation in the electron density in the vicinity of any given atom is computed as the superposition of individual effects due to each neighboring atom. This allows for an accurate, but also computationally simple, way to detect general trends in idealized multicomponent systems as are, for example, the systems presented in this work. The agreement between $a b$ initio methods and BFS, shown in Figure 1, is the foundation for the quality of the results found in a number of applications of the method to binary and multicomponent systems [28].

The BFS method for alloys is based on the concept that the energy of formation of a given atomic configuration is the sum of the individual atomic contributions, $\Delta H=$

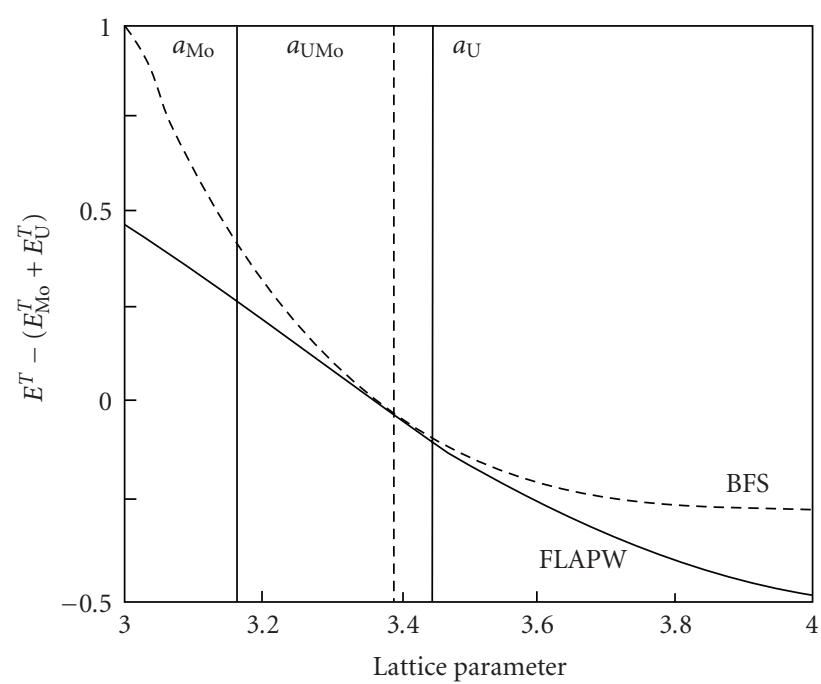

FIGURE 1: Comparison of the $a b$ initio (see text for the details of the calculations) results (solid curves) and BFS results (dashed curves) as a function of the lattice parameter (in $\AA$ ) for U-Mo in the B2 structure. The vertical lines indicate the equilibrium lattice parameters of $U$ and Mo in the bcc symmetry of the alloy (solid lines) and B2 U-Mo (dashed line), as computed by the ab initio code.

$\sum \varepsilon_{i}$. Furthermore, each contribution by atom $i, \varepsilon_{i}$, can be calculated as the sum of two terms: a strain energy, $\varepsilon_{i}^{S}$, computed in the actual lattice as if every neighbor of the atom $i$ were of the same atomic species $i$, and a chemical energy, $\varepsilon_{i}^{C}$, computed as if every neighbor of the atom $i$ were in an equilibrium lattice site of a crystal of species $i$, but retaining its actual chemical identity.

The computation of $\varepsilon_{i}^{S}$, using equivalent crystal theory (ECT) [27], involves three pure element properties for atoms of species $i$ : cohesive energy $\left(E_{C}\right)$, lattice parameter $\left(a_{o}\right)$, and bulk modulus $\left(B_{0}\right)$. These three parameters for each of the constituent elements are needed in the general derivative structure of the final alloy. Additional ECT parameters, $\alpha$ (a measure of the real average electron density), $l$ (a scaling length relating the cohesive energy, bulk modulus, and equilibrium lattice parameter), and $\lambda$ (a screening length for next-nearest-neighbors) that can be easily derived from $E_{C}, a_{0}$, and $B_{0}$, and $p$, related to the principal quantum number $n(p=2 n-2)$ [27].

The chemical energy, $\varepsilon_{i}^{C}$, accounts for the corresponding change in composition, considered as a defect in an otherwise pure crystal. The chemical defect deals with pure and mixed bonds, and only two additional perturbative parameters $\left(\Delta_{\mathrm{AB}}\right.$ and $\Delta_{\mathrm{BA}}$ where $(\mathrm{A}, \mathrm{B})$ could be any pair of elements that can be formed amongst them) are needed to describe these interactions [28]. A reference chemical energy, $\varepsilon_{i}^{C o}$, is also included to insure a complete decoupling of structural and chemical features. Finally, the strain and chemical energies are linked with a coupling function $g_{i}$, which ensures the correct volume dependence of the BFS chemical energy contribution. Therefore, the contribution of atom $i$ to the energy of formation of the system is given by

$$
\varepsilon_{i}=\varepsilon_{i}^{S}+g_{i}\left(\varepsilon_{i}^{C}-\varepsilon_{i}^{C o}\right) .
$$


TABLE 1: LAPW results for the lattice parameter, cohesive energy, and bulk modulus for the bcc phases of $\mathrm{U}, \mathrm{Al}, \mathrm{Si}, \mathrm{Mo}$, and C, the resulting ECT parameters [27] $p, \alpha, l$, and $\lambda$, and the BFS perturbative parameters $\Delta_{\mathrm{AB}}$ and $\Delta_{\mathrm{BA}}$.

(a) Single elements parameters

\begin{tabular}{|c|c|c|c|c|c|c|c|}
\hline & \multirow{2}{*}{ Lattice parameter $(\AA)$} & \multirow{2}{*}{ Cohesive energy $(\mathrm{eV})$} & \multirow{2}{*}{ Bulk modulus (GPa) } & \multicolumn{4}{|c|}{ ECT parameters } \\
\hline & & & & $p$ & $\alpha\left(\AA^{-1}\right)$ & $l(\AA)$ & $\lambda(\AA)$ \\
\hline $\mathrm{U}$ & 3.45012 & 5.55175 & 141.38 & 12 & 4.8689 & 0.31322 & 0.88015 \\
\hline $\mathrm{Al}$ & 3.23811 & 3.44327 & 69.13 & 4 & 1.76396 & 0.36414 & 1.02322 \\
\hline $\mathrm{Si}$ & 3.08731 & 4.07901 & 90.93 & 4 & 1.85741 & 0.35390 & 0.99446 \\
\hline Mo & 3.16156 & 6.66707 & 260.54 & 8 & 3.47728 & 0.26414 & 0.74223 \\
\hline $\mathrm{C}$ & 2.37957 & 3.62092 & 180.88 & 2 & 1.15350 & 0.26960 & 0.75758 \\
\hline
\end{tabular}

(b) BFS parameters $\Delta_{\mathrm{AB}}$ and $\Delta_{\mathrm{BA}}\left(\right.$ in $\left.\AA^{-1}\right)$.

\begin{tabular}{lccccc}
\hline $\mathrm{A} \backslash \mathrm{B}$ & $\mathrm{U}$ & $\mathrm{Al}$ & $\mathrm{Si}$ & $\mathrm{Mo}$ & -0.04373 \\
$\mathrm{U}$ & & -0.01356 & -0.04831 & -0.03351 & -0.024203 \\
$\mathrm{Al}$ & 0.06420 & & 0.02607 & -0.04488 & -0.024667 \\
$\mathrm{Si}$ & 0.05004 & -0.00526 & & -0.025460 \\
$\mathrm{Mo}$ & 0.15898 & 0.10065 & 0.27565 & -0.03541 & -0.026109 \\
$\mathrm{C}$ & -0.07545 & -0.04341 & -0.04188 & \\
\hline
\end{tabular}

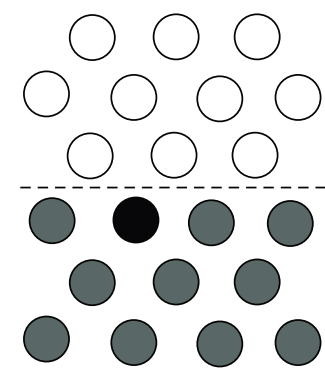

0

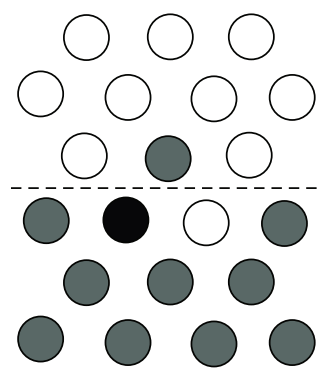

0.046

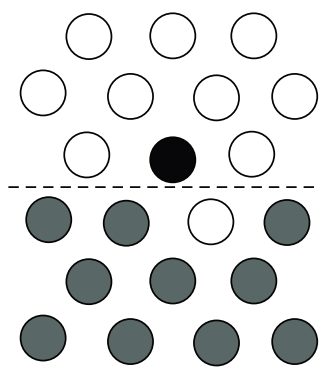

0.185

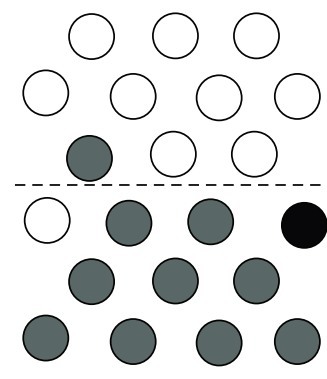

$-0.028$

FIGURE 2: Configuration with a single Mo atom (black circle) located in an Al/U (open circle and grey circle, respectively) interface site. The difference in energy (in $\mathrm{eV}$ ) with respect to the reference state (left panel) is shown for each case.

All the necessary single element parameters are listed in Table 1. We refer the reader to [31] for a discussion of the BFS method, its definitions, operational equations, and their implementation, and [22] for a discussion and validation of the parameters. It should be noted that differences in the USi parameters between previous applications [20] are not an indication of lack of universality, as they only reflect further adjustments when new experimental information was used to validate them.

In all cases, the ground state properties of each element (in the bcc symmetry) and the corresponding BFS parameters were calculated using the linearized-augmented plane wave method (LAPW) as implemented in the WIEN2k code [29]. This code uses the full-potential APW + lo method that makes no shape approximation to the potential or density. The generalized gradient approximation (GGA) of Perdew et al. [32] was used for the correlation and exchange potentials.
The atomic sphere radii, $R_{\mathrm{MT}}$, selected for the elements considered in this work were 1.8-1.9 bohr, except for $\mathrm{U}$ for which a value of 2.5 bohr was used. Local orbital extensions were included for the semicore states of all the elements, including $\mathrm{U}$. The basis set size $R_{\mathrm{MT}} K_{\max } \quad$ (where $R_{\mathrm{MT}}$ is the smallest atomic sphere radius inside the cell and $K_{\max }$ is a cut-off for the basis function wave vector) were chosen as 9 for pure elements and the B2 compounds used in this work. The cut-off in the charge density Fourier expansion, $G_{\max }$, was selected as $22 \mathrm{Ry}^{1 / 2}$. The maximum $l$ values selected for partial waves inside the spheres and for the non muffin-tin matrix elements are $l_{\max }=10$ and $l_{\max }=4$, respectively. A mesh of 286 and 165 special k-points was taken in the irreducible wedge of the Brillouin zone for pure elements and B2 compounds, respectively. The iteration process was repeated until the calculated total energy converged to less than $0.01 \mathrm{mRy} / \mathrm{cell}$. 


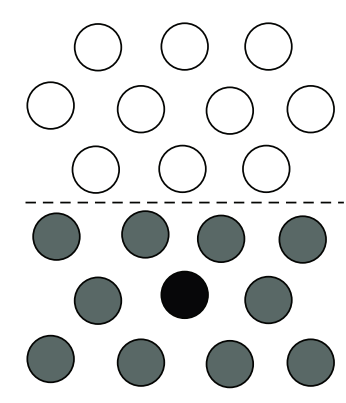

0

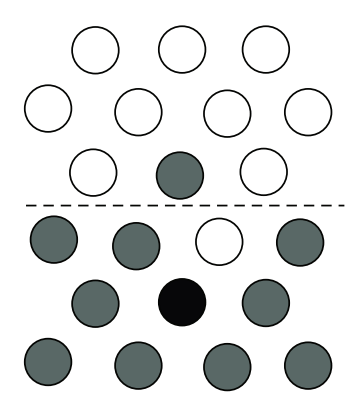

$-0.016$

FIGURE 3: Configuration with a single Mo atom (black circle) located in an $\mathrm{Al} / \mathrm{U}$ (open circle and grey circle, respectively) subinterface site. The difference in energy (in eV) with respect to the reference state (left panel) is shown.

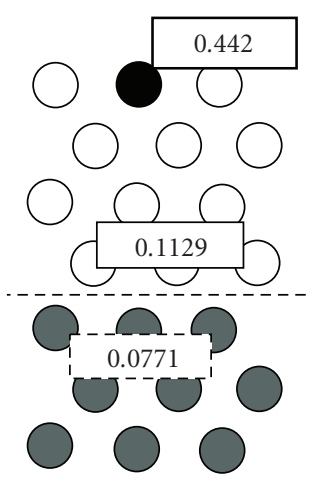

0

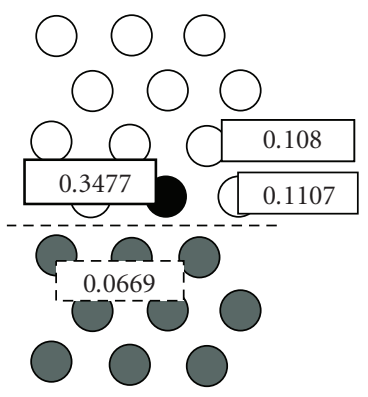

$-0.1137$
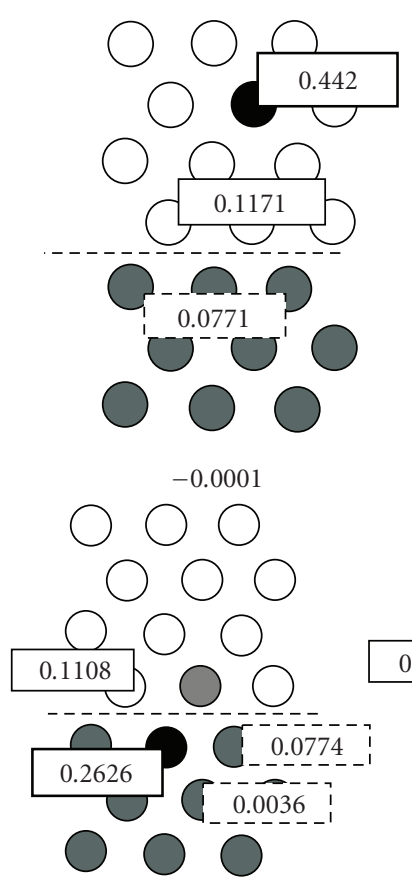

$-0.2123$
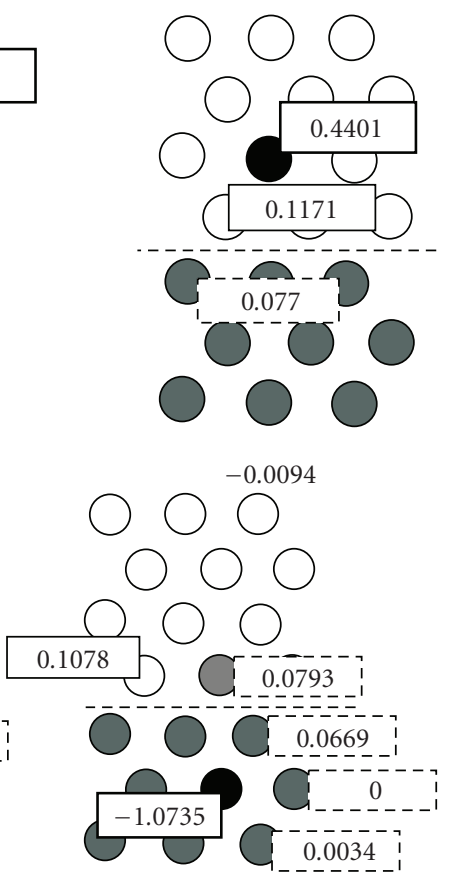

$-1.4441$

FIgURE 4: Energetics of the computational cell as a Si atom (black disk) goes from the Al (open circle) matrix to the U (grey circles) fuel. The chemical and total energy contributions of the $\mathrm{Si}$ atom are shown in each case in a thick rectangle. The total energies of $\mathrm{U}$ or $\mathrm{Al}$ atoms are indicated in dashed and thin rectangles, respectively. The difference in energy (in eV) with respect to the lowest energy state (left top corner) is noted below each graph.

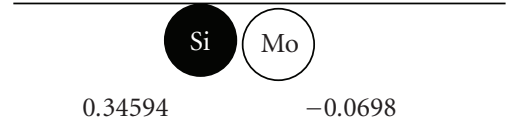

(0.0356)

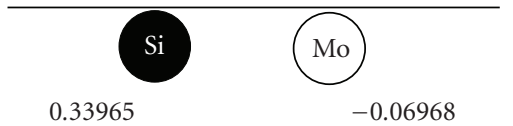

$(0.0154)$

(b)

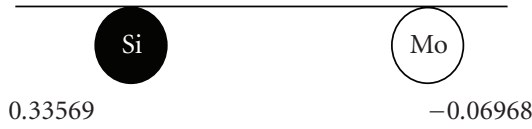

(0)

(c)

Figure 5: Chemical and total (in parenthesis) energy contributions (in eV) of an Al/U interface with a Si (black disk) and an Mo atom in the top fuel layer, for different separations: (a) as nearest-neighbors, (b) as next-nearest-neighbors, and (c) far from each other. 


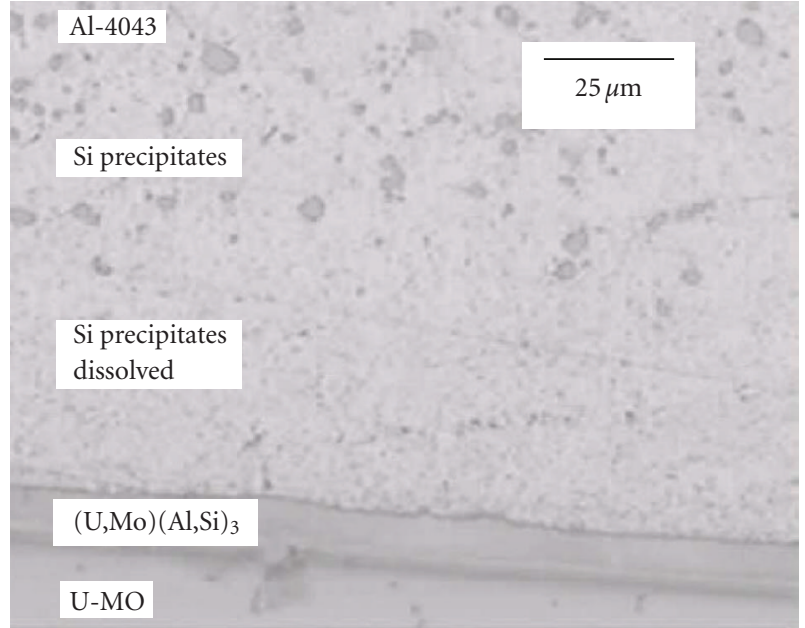

(a)

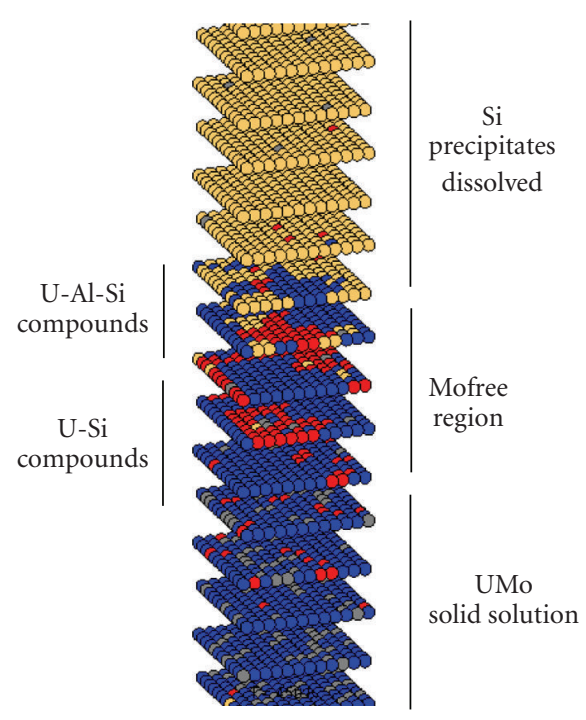

(b)

FIGURE 6: (a) Experimental sample of the Al-5.2 wt\% Si/U-7 wt \% Mo interface showing the zone of depletion of Si precipitates near the interdiffusion layer [29]. (b) Simulations of the Al-5 wt $\% \mathrm{Si} / \mathrm{U}-7 \mathrm{wt} \% \mathrm{Mo}$ interface at $T=500 \mathrm{~K}$ showing the main experimental results, such as: (1) Si depletion in Al side, (2) the tendency to local ordering in the zone between $\mathrm{Al}$ and U-Mo, and (3) an unexpected interaction between Mo and Si which inhibits the Si diffusion to deeper layers in the U-Mo solid solution, improving the Si stopping power for Al diffusion. $\mathrm{Al}, \mathrm{Si}, \mathrm{U}$, and $\mathrm{Mo}$ atoms are denoted with yellow, red, blue, and grey circles, respectively. The experimental result corresponds to a room temperature observation of a sample treated at $550^{\circ} \mathrm{C}$ for 2 hours [30].

As a side note, we note that the GGA approximation is accurate enough for the calculation performed in this work, with just a $0.8 \%$ error in the prediction of the lattice parameter of $\mathrm{U}(\mathrm{bcc})$ and similar differences for U-Mo, indicative that the $5 f$ electrons are properly located near the Fermi level. The lattice parameter would be very different from the experimental one if some $5 f$ electrons were localized in $\mathrm{U}(\mathrm{bcc})$, as they cannot participate in the cohesion of the solid.

\section{Discussion and Results}

Previous theoretical studies [20-25], based on atomistic simulations using BFS method for alloys, describe the individual role of each atom in the interface Al-Si/UMo, provide an explanation for the trends observed experimentally, and propose alternatives to the accepted solution for the high-density uranium fuels. These results lead to the conclusion that it might be possible to describe the complex problem of the interaction between several elements within a rather simple and straightforward modeling framework. It is important to remark here that the forthcoming atom-by-atom analyses and simulations are restricted to a rigid bcc cell with the lattice parameter of the $\mathrm{U}$ portion terminating in the (100) orientation (similar results were obtained for the (110) and (111) orientations). It should be noted, however, that the use of a rigid bcc cell is a limitation of the currently available software, and not an intrinsic limitation of the method. For the purpose of this study, focused on determining qualitative trends and changes of the U-Mo solid solution behavior for different additives, the proposed framework is largely appropriate.

Temperature-dependent simulations throughout this work are based on the standard Monte Carlo-Metropolis algorithm, where all atoms are allowed to perform every possible exchange, with such exchange given a probability factor determined by the difference in energy before and after the exchange. As such algorithm results in the ideal equilibrium state (infinite diffusion), a variant of this method was also used, based on exchanges limited to nearest-neighbor sites and a probability factor proportional to the available thermal energy [31], thus providing a more accurate description of experimental results. Rigid cells of 8600 atoms were used with periodic boundary conditions, subjected to ascending temperature cycles from $1 \mathrm{~K}$ to $800 \mathrm{~K}$.

A note of caution for the following discussion relates to the use of the term "diffusion". In all the calculations in this section, we just compare the energetics of different configurations that differ in the location of specific atoms, thus providing information on the thermodynamic driving force alone, ignoring the kinetics and actual diffusion mechanisms. As such, in this paper the term "diffusion" will be used in an approximate fashion to describe exclusively the outcome in successive steps of a simulation based on the BFS method for the energetics and Monte Carlo methods for the configurational contributions. Lastly, in what follows, we will loosely use the concept of an atom A "attracting" or "repelling" an atom B as a reflection that atom A lowers or raises its individual energy contribution to energy of formation $\Delta H$ in the presence of atom $\mathrm{B}$, and vice versa. 

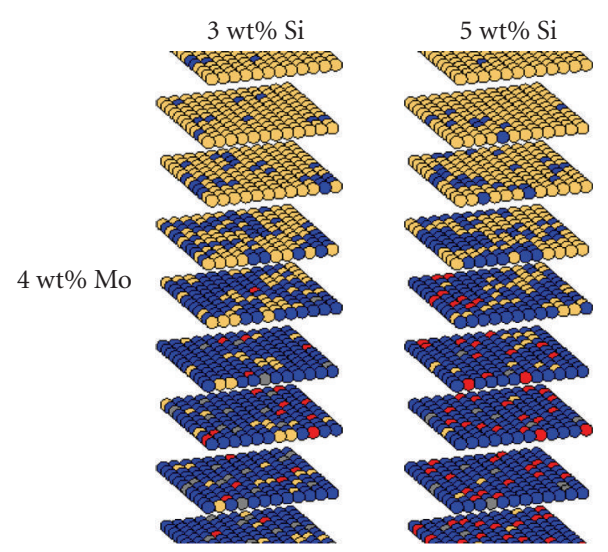

(a)
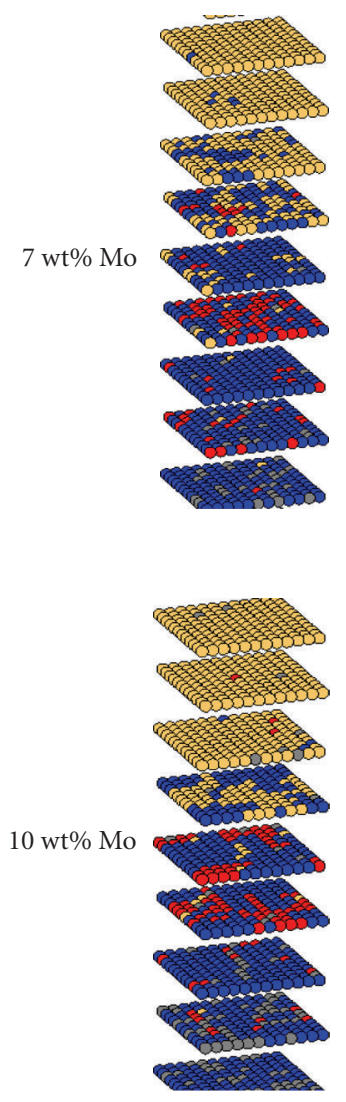

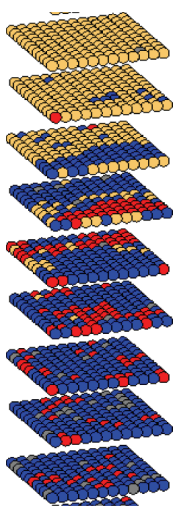

(b)

$7 \mathrm{wt} \% \mathrm{Si}$
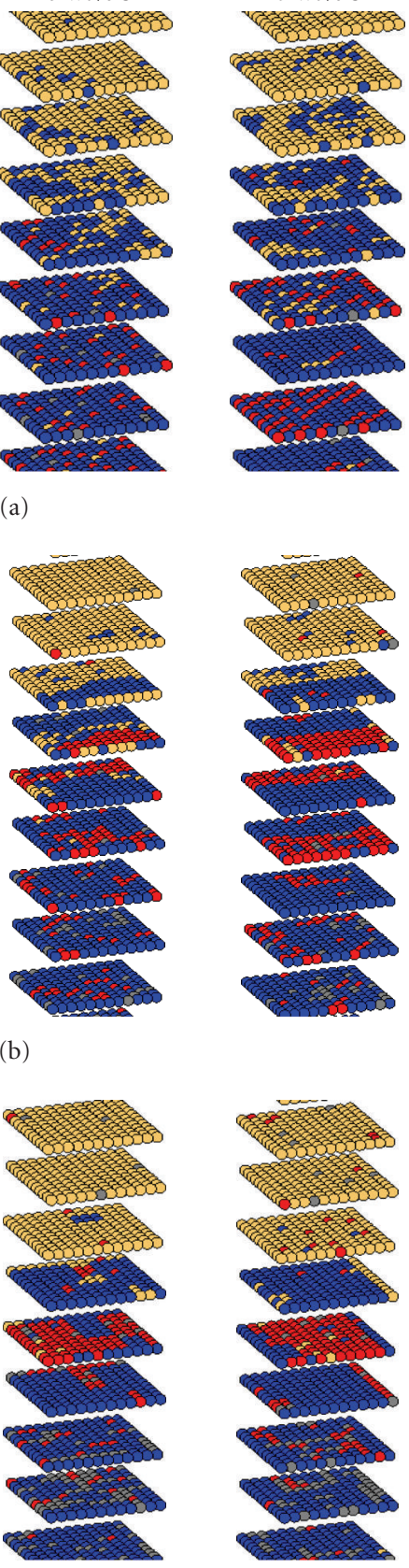

(c)

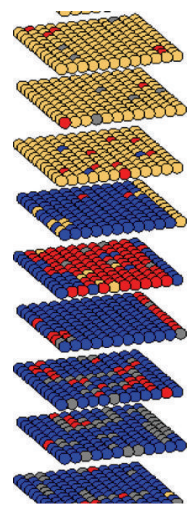

FIgUre 7: Equilibrium state of the computational cell at $T=450 \mathrm{~K}$ for (from left to right) 3, 5, and $7 \mathrm{wt} \% \mathrm{Si}$ and for 4, 7, and $10 \mathrm{wt} \%$ Mo. Al, Si, U, and Mo atoms are denoted with yellow, red, blue, and grey circles, respectively. The simulations show that the Si stopping power is due to the interplay between $\mathrm{Si}$ and Mo and not only to Si additions. The original location of the interface (at the onset of the simulation) corresponds to the middle of each figure.

3.1. Summary of the Atom-by-Atom Analysis of the Al/UMo Interface. The atom-by-atom analysis of the Al/U-Mo interface identifies two main driving forces that control $\mathrm{Al}$ diffusion in the presence of Mo atoms in the interface. First, due to substantial energy gains for the $\mathrm{U}$ atom, the diffusion

of $\mathrm{Al}$ is inhibited by the presence of Mo in the interface sites, as shown in Figure 2 (unless the $\mathrm{Al}$ atom is far from the Mo atoms, in which case, it is controlled by $\mathrm{U}$ atoms in the interface sites). Also, it is strongly favored by the presence of isolated Mo in subsurface sites, as shown in Figure 3. Second, the beneficial effect produced by the isolated Mo in subsurface sites diminishes with Mo concentration, as it is more likely to find Mo atoms or clusters in the interface. To model the clustering effect of Mo in the diffusion of $\mathrm{Al}$, a small square patch of $3 \times 3$ Mo atoms located in interface sites was considered. The exchange of an $\mathrm{Al}$ atom to the interface raises the total energy by $1.094 \mathrm{eV} /$ atom, while if the same Mo cluster is located in the subsurface plane, the energy raises only by $0.0355 \mathrm{eV} /$ atom. In agreement with experiment [2], $\mathrm{Al}$ interdiffusion is prevalent in Mo-deficient regions of the U-Mo substrate.

3.2. Summary of the Role of $\mathrm{Si}$ in the Al/U-Mo Interface. As the number of alloying additions grows, it is inevitable to deal with secondary effects besides the individual role that each addition could have in the original system that affect, change, and sometimes invalidate, their original purpose. But it is also possible that unexpected and viable new alternatives could emerge. This is the case for Si additions, which induce a somewhat unexpected behavior by changing the role of the atoms present in the interface.

The most interesting result is that the chemical energy of $\mathrm{Si}$ goes from significantly positive for $\mathrm{Si}$ in $\mathrm{Al}$ (repulsion of $\mathrm{Al}$ ) to negative (attraction of $\mathrm{U}$ ) for $\mathrm{Si}$ in $\mathrm{U}$, as shown in Figure 4, resulting in more favorable total energy contributions than those seen when $\mathrm{Al}$ penetrates $\mathrm{U}[20,22]$. The atom-by-atom analysis reveals that Si prefers first the $\mathrm{U}$ bulk $(-1.4441 \mathrm{eV})$ and second a position surrounded by $\mathrm{U}$ and $\mathrm{Al}$ atoms as nearest-neighbors $(\mathrm{NN})(-0.2123 \mathrm{eV})$, a scheme that explains the observed tendency to form $\mathrm{U}(\mathrm{Al}$, $\mathrm{Si})_{3}$ compounds if the first option is inhibited, for example, by the presence of Mo atoms. However, $\mathrm{Al}$ prefers to occupy sites far from Si atoms in the interface sites, a behavior that explains the stopping power of $\mathrm{Si}$ for $\mathrm{Al}$ diffusion.

An unexpected interaction is found between Mo and $\mathrm{Si}$ which makes the presence of $\mathrm{Si}$ in deeper layers in the U-Mo solid solution energetically unfavorable. Si and Mo prefer to be far away from each other, as the energy increases (mostly due to $\mathrm{Si}$ ) when they are closer, as shown in Figure 5. Conversely, Mo is only marginally affected by the presence of $\mathrm{Si}$. The fact that $\mathrm{U}$ raises its energy for any of these schemes clearly suggests that $\mathrm{Si}$ is the atom that drives the energetics of the preferred atomic configurations in the quaternary system. Increasing the concentration of $\mathrm{Si}$ in the U-Mo solid solution makes it more likely to find Si clusters in the surface or in the subsurface plane. This effect can be modeled with a simple $3 \times 3$-atom patch of $\mathrm{Si}$ in the top fuel layer. Al finds a considerable energy barrier to exchange sites in the center of the cluster $(0.0229 \mathrm{eV} /$ atom $)$ or in its edge $(0.0175 \mathrm{eV} /$ atom $)$. Still, the energy decreases if $\mathrm{Al}$ exchanges sites with $\mathrm{U}$ atoms located in the periphery of the Si cluster $(-0.0071 \mathrm{eV} /$ atom $)$. A different situation arises if the cluster is placed in the subsurface plane as a high energy barrier $(2.61 \mathrm{eV} /$ atom $)$ precludes $\mathrm{Al}$ diffusion into the $\mathrm{U}$ bulk. 

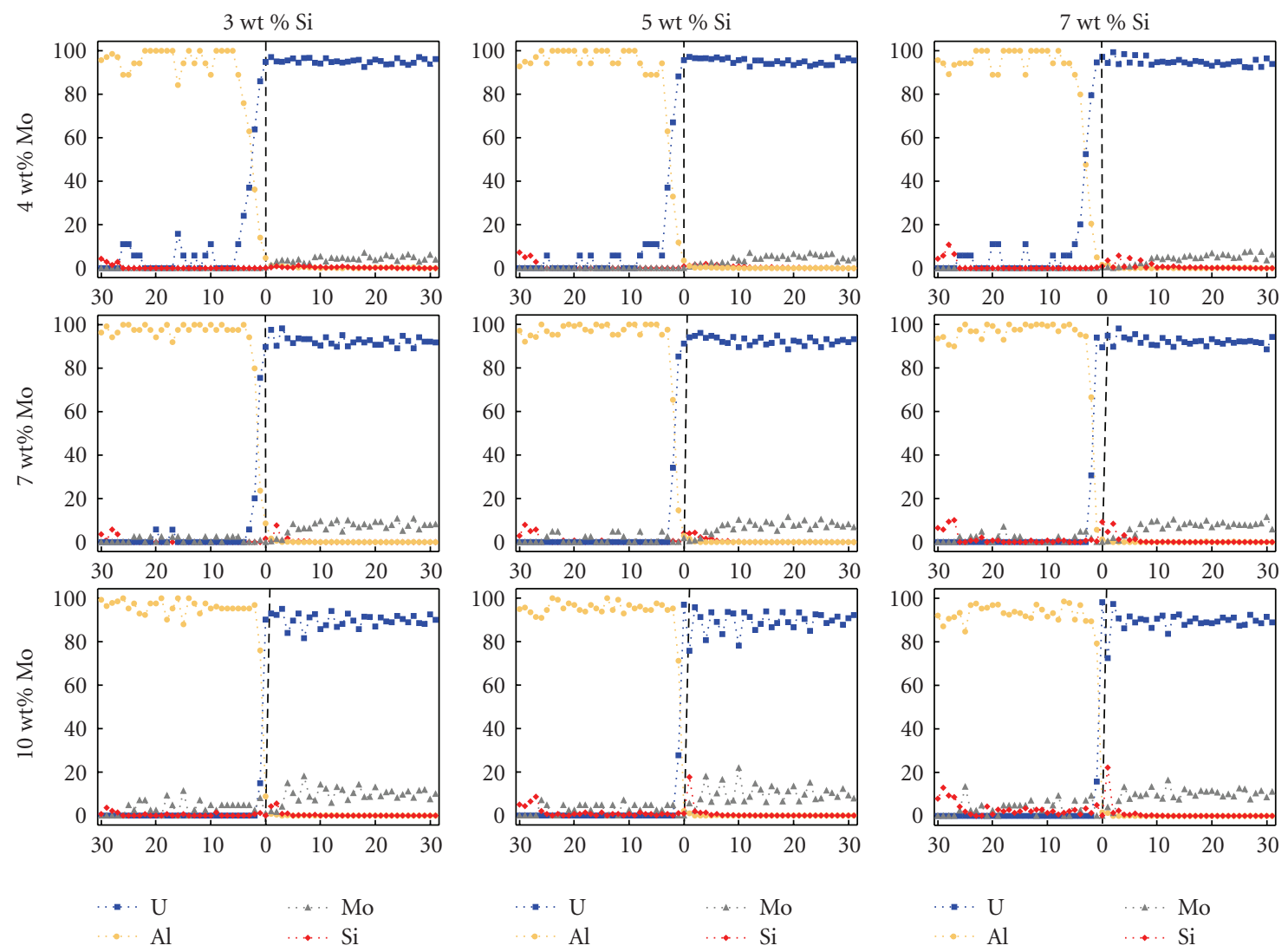

Figure 8: Composition profiles of the computational cells at $T=450 \mathrm{~K}$ shown in Figure 7 for (from left to right) 3, 5, and $7 \mathrm{wt} \% \mathrm{Si}$, and (from top to bottom) 4, 7, and $10 \mathrm{wt} \% \mathrm{Mo}$. Al, Si, U, and Mo atoms are denoted with yellow, red, blue, and grey circles, respectively. The original location of the interface (at the onset of the simulation) corresponds to the label " 0 ". The change of the concentration profile width with Mo and Si content is shown. Increasing numbers to the left and to the right of this reference layer denote matrix and fuel layers.

In summary, the atom-by-atom analysis shows that the basic features characterizing the real system, observed experimentally, can be identified. These include the depletion of $\mathrm{Si}$ in $\mathrm{Al}$ regions close to the interface, the trend indicating formation of interfacial multicomponent compounds, and the much reduced concentration of $\mathrm{Al}$ in $\mathrm{U}-\mathrm{Mo}$ due to the high Si concentration. The presence of $\mathrm{Si}$ in the subsurface plane is the root of the $\mathrm{Si}$ stopping power for $\mathrm{Al}$ diffusion observed experimentally.

\subsection{Evolution of the System Al-Si/U-Mo with Temperature.} Once the individual atomic role in the interface is understood and the overall behavior is found to be in agreement with the experimental results, it is possible to describe the simultaneous effect on the structure of the interface of adding $\mathrm{Si}$ to $\mathrm{Al}$ and $\mathrm{Mo}$ to $\mathrm{U}$, as a function of temperature. In this section, we will also present the effect of Si deposition to simulate the coating of the U-Mo particles, an alternative to $\mathrm{Si}$ addition to $\mathrm{Al}$ for generating diffusional barriers.

Experimental results for $\mathrm{Al}-5 \mathrm{wt} \% \mathrm{Si} / \mathrm{U}-7 \mathrm{wt} \% \quad \mathrm{Mo}$ suggest that $\mathrm{Si}$ additions to $\mathrm{Al}$ introduce important changes in relation with the phases found inside the interaction layer: the U-Al-Si compound was identified as $\mathrm{U}(\mathrm{Al}, \mathrm{Si})_{3}(\mathrm{cP} 4$,
$\mathrm{Cu}_{3} \mathrm{Au}$ type) near the $\mathrm{Al}$ alloy and the U-Si compound as $\mathrm{U}_{3} \mathrm{Si}_{5}$ (hP3, $\mathrm{AlB}_{2}$ type). The most noticeable result is the complete depletion of $\mathrm{Si}$ in $\mathrm{Al}$ regions close to the interface [30].

Although the software limitation of performing simulations on a rigid bcc cell prevents us from properly determining the structure and composition of these compounds, the simulation shown in Figure 6 reproduces the main features seen in the experiment at finite temperature: (1) formation of Si precipitates far from the reaction layer, (2) local ordering trend, and (3) an $\mathrm{Al}$ concentration profile consistent with inhibited diffusion in the fuel. The most striking result, a consequence of the interaction between all four elements, is the complete depletion of $\mathrm{Si}$ in $\mathrm{Al}$ regions close to the interface, a result in excellent agreement with experiment. Additional effects due to the interactions between the participating elements are also observed. The most noticeable is the interaction between $\mathrm{Mo}$ and $\mathrm{Si}$, resulting in a region free of $\mathrm{Mo}$ and $\mathrm{Al}$ where $\mathrm{Si}$ (in the majority) forms compounds. This effect, where Mo inhibits Si diffusion, is proportional to the concentration of Mo, thus allowing for changes in the composition of the locally ordered domains. Indeed, for very low Mo content the $\mathrm{Si}$ atoms diffuse deeply into the $\mathrm{U}$ 

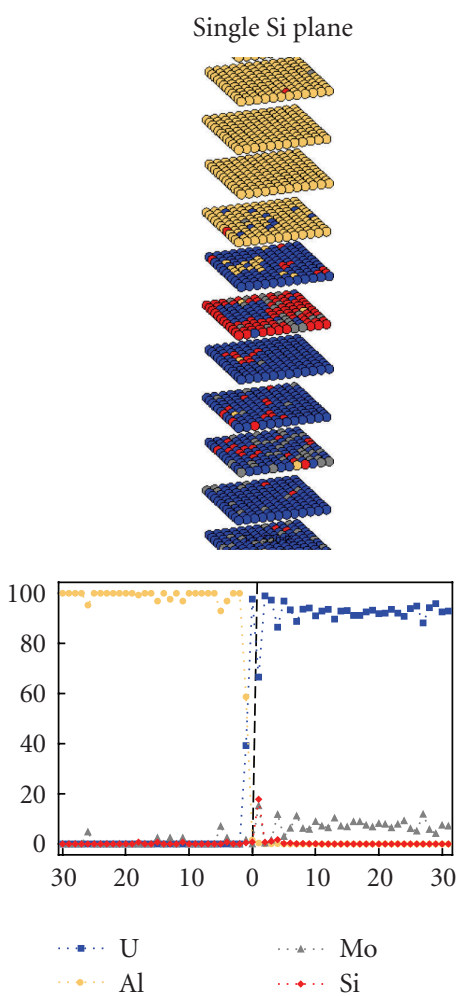

(a)
Al-5\% wt Si/U-7 wt $\%$ Mo
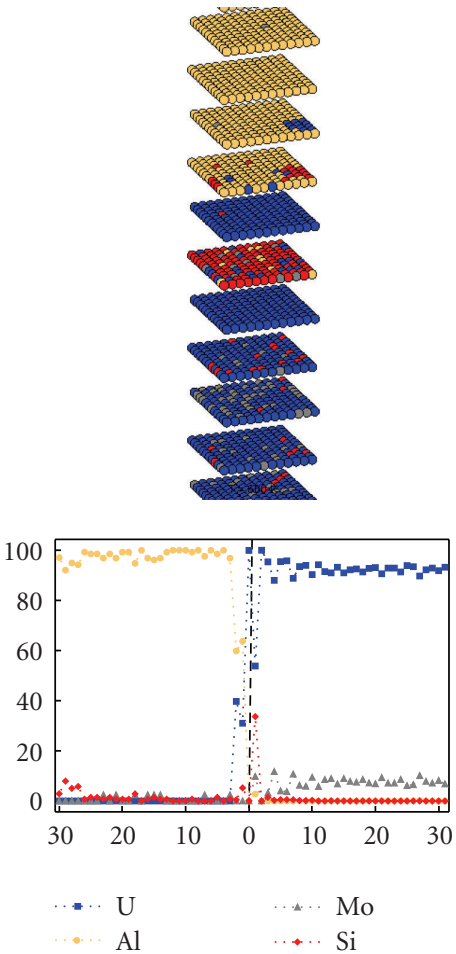

(b)
Two Si planes
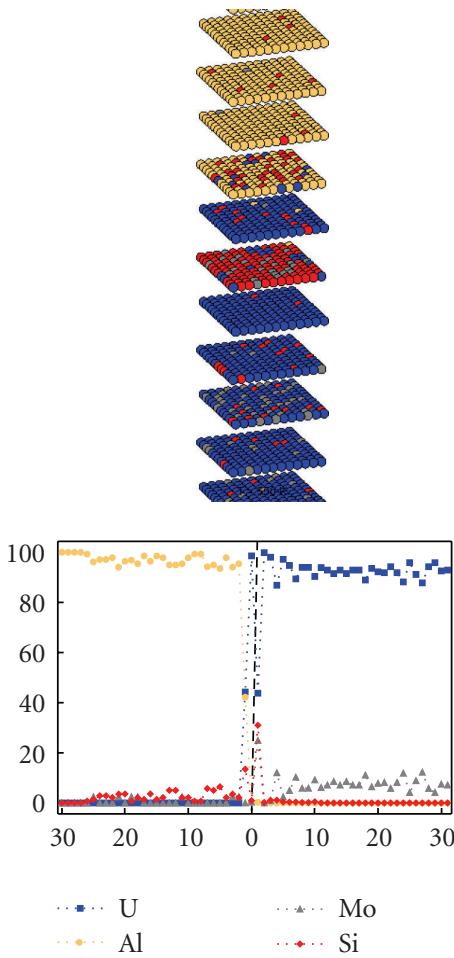

(c)

FIgure 9: Monte Carlo simulation results for $\mathrm{T}=450 \mathrm{~K}$ for (a) a single Si coating plane, (b) the usually accepted $\mathrm{Al}-5 \mathrm{wt} \% \mathrm{Si} / \mathrm{U}-7 \mathrm{wt} \% \mathrm{Mo}$ case, and (c) two Si coating planes, and their corresponding concentration profiles (in wt\%). U, Mo, Al, and Si atoms are denoted with blue, grey, yellow, and red spheres (cells) or lines (profiles). The original location of the interface (at the onset of the simulation) corresponds to the label " 0 ".

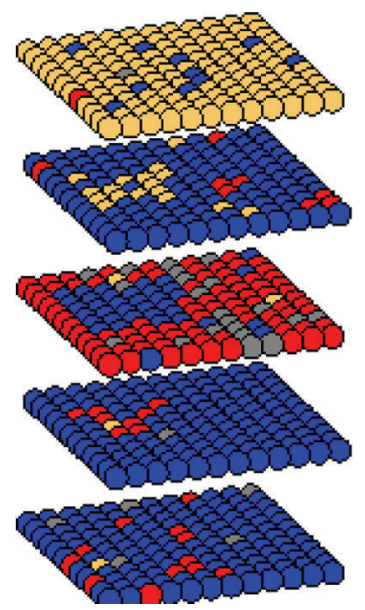

Figure 10: Effect of the (U,Si) local ordering on $\mathrm{Al}$ diffusion. In agreement with the atom-by-atom analysis, the Si atoms have an increased stopping power if they are located in subsurface U-rich planes. 

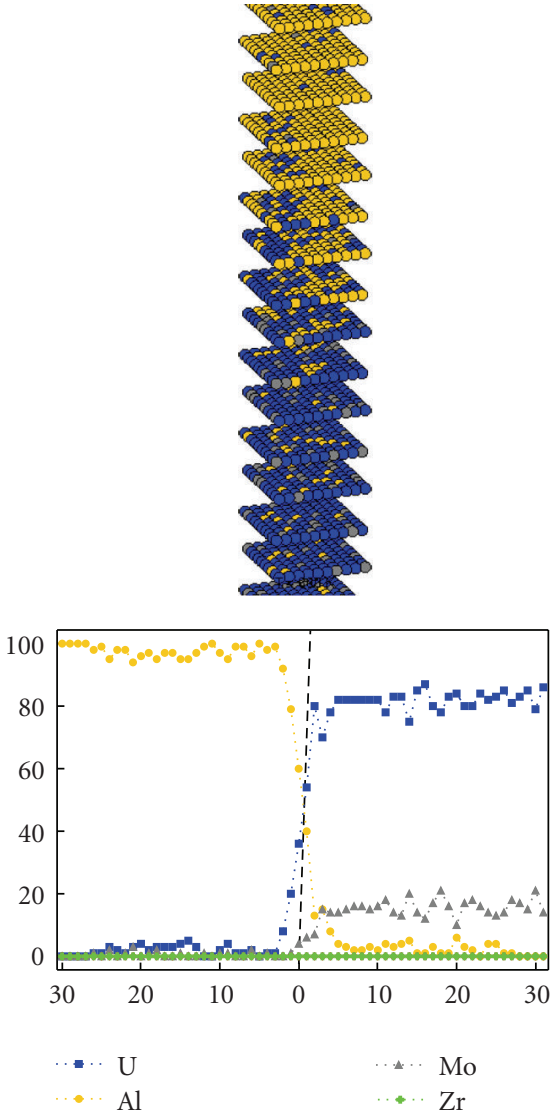

(a)
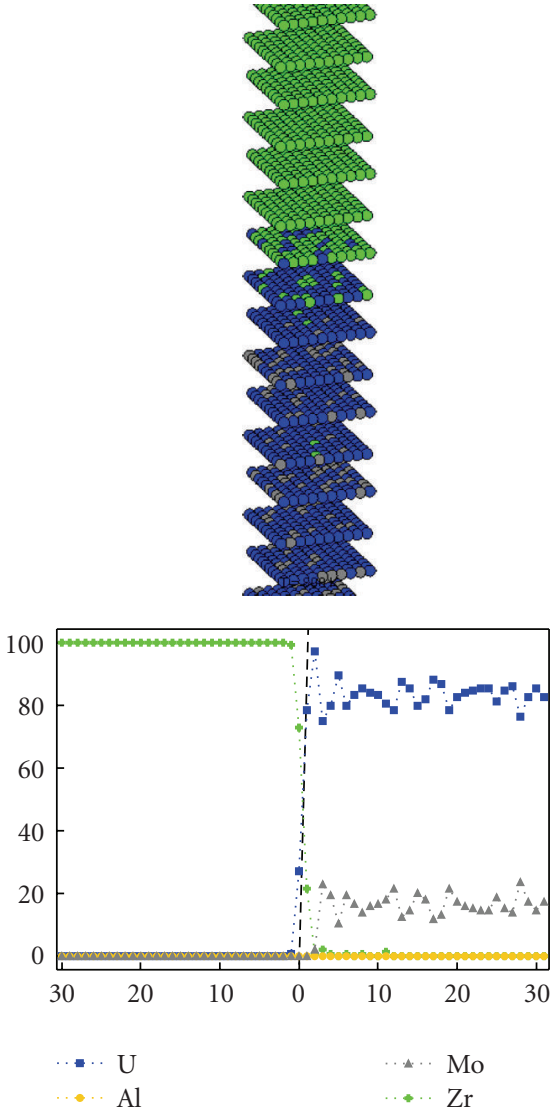

(b)

Figure 11: Equilibrium state of the computational cell at $T=800 \mathrm{~K}$ for (a) Al/U-7 wt $\%$ Mo and (b) Zr/U-7 wt $\%$ Mo, and their corresponding concentration profiles (in wt\%). U, Mo, Al, and $\mathrm{Zr}$ atoms (and profiles) are denoted in blue, grey, yellow, and green, respectively. The original location of the interface (at the onset of the simulation) corresponds to the label " 0 ".

side of the interface. The combined effect of $\mathrm{Si}$ and Mo is an $\mathrm{Al}$ concentration profile consistent with a decrease in $\mathrm{Al}$ diffusion into the U-Mo solid solution.

3.4. Minimum Amount of Si Addition to the Al Matrix. The description of the basic features of the atomic behavior is found to be in agreement with the experimental results, thus raising the necessary confidence in the theoretical methodology. The next natural step is to find the optimum amount of Si and Mo needed to generate a good diffusion barrier to avoid interdiffusion between the four elements, recalling the fact that the term diffusion is used in this work to describe the outcome in successive steps of a simulation. Figure 7 shows a set of simulations for $T=450 \mathrm{~K}$ where the Si and Mo concentrations were changed from $3 \mathrm{wt} \% \mathrm{Si}$ to $7 \mathrm{wt} \% \mathrm{Si}$ and from $4 \mathrm{wt} \%$ Mo to $10 \mathrm{wt} \% \mathrm{Mo}$, respectively. Figure 8 shows the corresponding concentration profiles. These figures allow for the analysis of the effect of different amounts of Si and Mo on the trend to local ordering and the diffusion of the elements between the two zones.
The increase in stopping power for $\mathrm{Si}$ is evident in the $4 \mathrm{wt} \%$ Mo case, as there are noticeable changes with $\mathrm{Si}$ concentration in the features of the (U, Si) local ordering formed in the interface (located in the middle of each figure), in the size of the Mo free zone, and in the $\mathrm{Al}$ and Si diffusion. For any Si concentration the local ordering arrangements formed in the interaction zone are unable to act as an energy barrier for $\mathrm{U}$, although it is more effective for the $\mathrm{Al}$ atoms.

For $7 \mathrm{wt} \% \mathrm{Mo}$, it is possible to observe the effect of $\mathrm{Si}$ additions by analyzing the growth of the Mo-free zone and $\mathrm{Al}$ diffusion with Si content. The effect is optimum for a content of $7 \mathrm{wt} \% \mathrm{Si}$, where the local ordering formed in the interaction zone constitutes an effective energy barrier for $\mathrm{Al}$ and $\mathrm{U}$, and a bit less effective for Mo.

For $10 \mathrm{wt} \% \mathrm{Mo}$, there is clear evidence of the Si stopping power for $\mathrm{U}$ and $\mathrm{Al}$ diffusion, although it is less efficient in avoiding Mo migration. It is also observed that Si diffusion to the interaction zone is diminished due to the $(\mathrm{U}, \mathrm{Si})$ compound formation in the interaction zone that precludes $\mathrm{Si}$ movement. This is a clear indication that $7 \mathrm{wt} \% \mathrm{Si}$ is too much for a $10 \mathrm{wt} \%$ Mo concentration, an amount that 
Al-5 wt $\%$ Si/U-7 wt $\%$ Mo
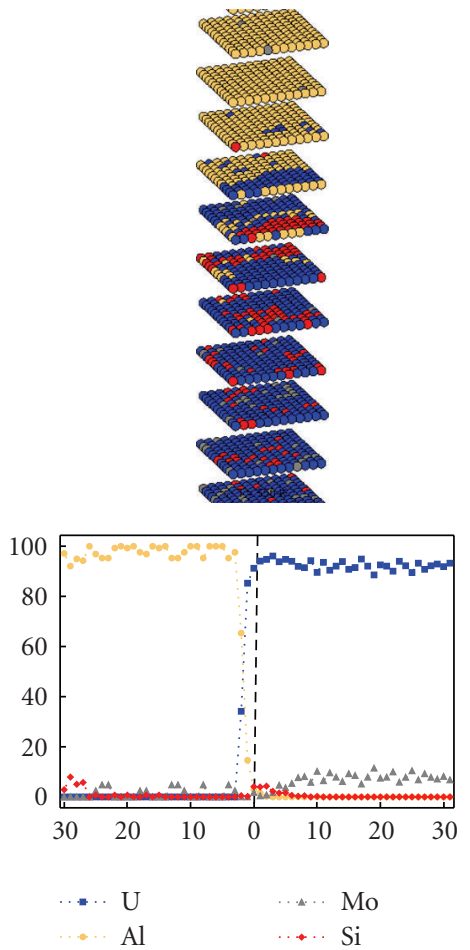

(a)
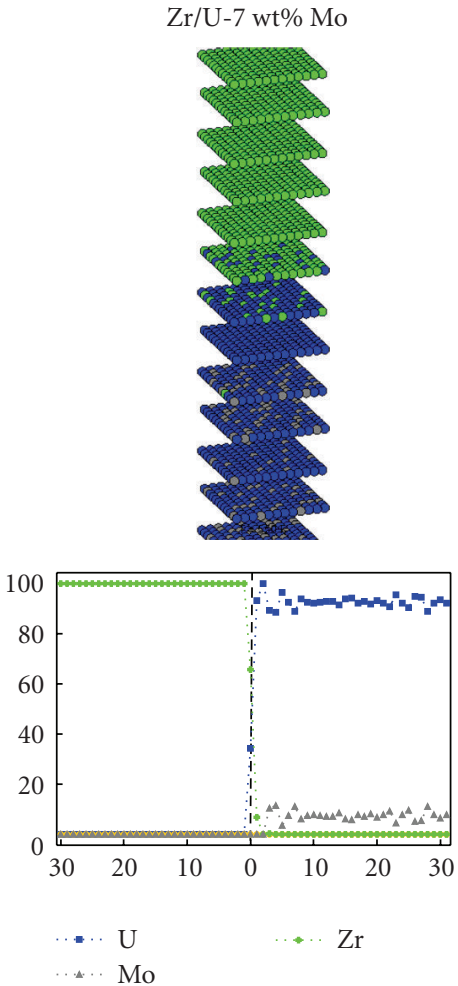

(b)
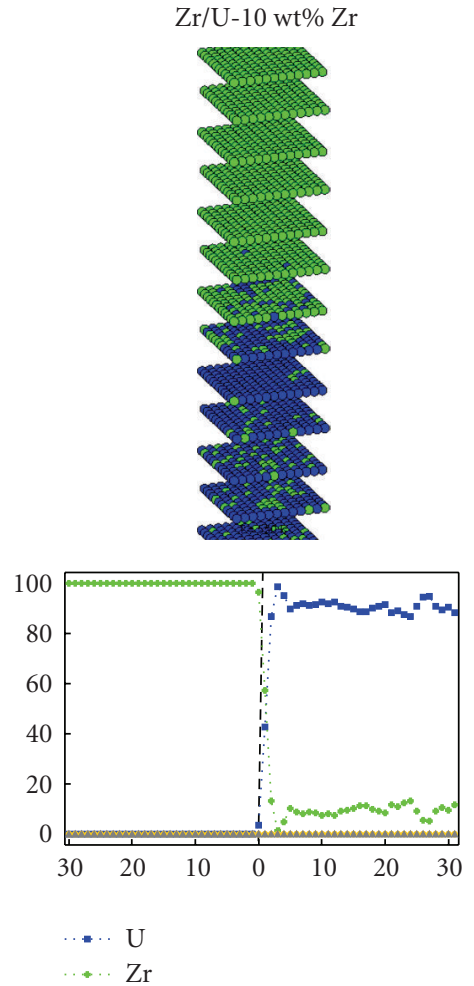

(c)

FIGURE 12: Equilibrium state of the computational cell at $T=550 \mathrm{~K}$ for (a) Al-5 wt\% Si/U-7 wt\% Mo, (b) Zr/U-7 wt\% Mo, and (c) Zr/U$10 \mathrm{wt} \% \mathrm{Zr}$, and their corresponding concentration profiles (in wt $\%$ ). The original location of the interface (at the onset of the simulation) corresponds to the label " 0 ". $\mathrm{U}, \mathrm{Mo}, \mathrm{Al}$, and $\mathrm{Zr}$ atoms (and profiles) are denoted in blue, grey, yellow, and green, respectively.

has detrimental effects for reprocessing plants. Excessive Mo migration to the $\mathrm{Al}$ zone is also observed. Probably, a detrimental effect could be induced in the interaction zone as some authors attributed the poor behavior of the fuel under irradiation to Mo presence in the Al-rich zone [19]. A stopping power similar to the combination $5 \mathrm{wt} \%$ $\mathrm{Si}$ and $7 \mathrm{wt} \%$ Mo is recovered for $10 \mathrm{wt} \% \mathrm{Si}$ and $10 \mathrm{wt} \%$ Mo.

It is clear from the simulation analysis that there is an optimum Si and Mo content, located between 5-7 wt \% Si for $7 \mathrm{wt} \% \mathrm{Mo}$, to meet the goal of diminishing the interface-growing kinetics and the formation of unwanted compounds. The theoretical modeling shows that the $\mathrm{Si}$ stopping power is due to the interplay between $\mathrm{Si}$ and Mo, and not only to Si, as it is usually accepted.

3.5. Si Coating of U-Mo Particles. There is one other alternative to using $\mathrm{Si}$ as an additive to $\mathrm{Al}$, namely, coating the fuel particles with one or more elements or compounds with the aim of generating diffusion barriers in the interaction zone. This alternative was rejected in 2004 [33] due to the thickness of the deposition necessary before the coating becomes an active and effective barrier under irradiation, and due to the negative effects of the rolling process of fuel fabrication in the barrier behavior if the coating has brittle compounds, such as some Si compounds. The simulation reflects the fact that a small fraction of a single Si plane, equivalent to $3.5 \mathrm{wt} \% \mathrm{Si}$ in our simulation cell, is necessary to obtain the same effect as adding $5 \mathrm{wt} \% \mathrm{Si}$ to the $\mathrm{Al}$ matrix. An experimental study based on the coating of the U-Mo particles was interrupted in CNEA in 2007 [34]. Currently, the SELENIUM project brought back this idea to improve the recovering of the UMo particles in an efficient and controlled way [19].

Figure 9 shows the simulation results for one and two planes of $\mathrm{Si}$, compared to the usually accepted composition Al-5 wt $\%$ Si/U-7 wt\% Mo. The simulations show that the interplay between Si and Mo, the source for the behavior observed experimentally, remains unaltered for both alternatives: $\mathrm{Si}$ dissolved in $\mathrm{Al}$ or in the $\mathrm{Si}$ coating. The stopping power effect of the $(\mathrm{U}, \mathrm{Si})$ local ordering is clearly seen already for just one Si plane in the central patch of the simulation shown in Figure 10.

3.6. Alternatives to Si Addition to the Al Matrix. As previously discussed, recent developments on the stabilization of U-Mo fuel have focused almost exclusively on the addition of Si to the $\mathrm{Al}$ matrix of the fuel. However, there are other solutions found theoretically, such as the use of Zircaloy as the matrix element instead of $(\mathrm{Al}, \mathrm{Si})$ alloy [23], or the use of $\mathrm{C}$ coating of the U-Mo particles instead of Si [25]. The first alternative was successfully verified in in-pile experiments [34] while the second remains open for experimental validation. 


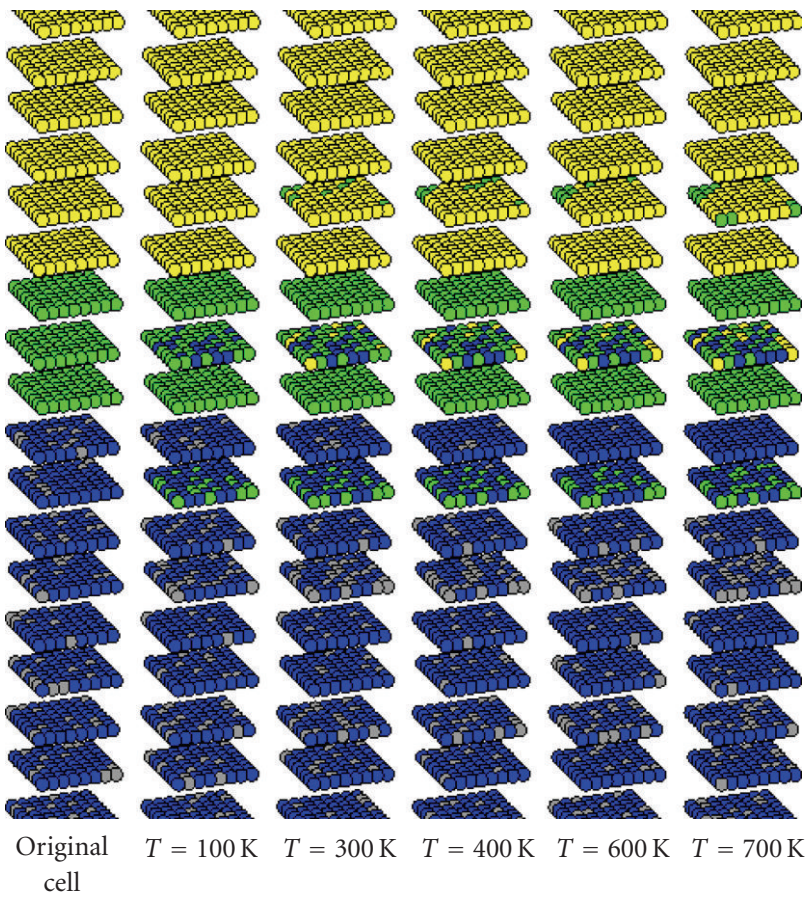

(a)
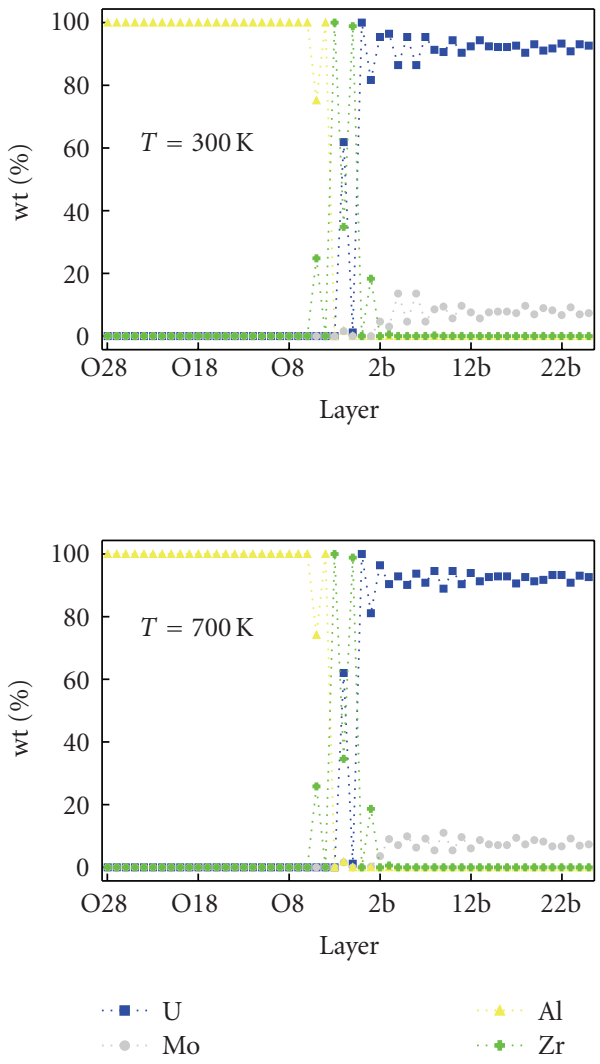

(b)

FIGURE 13: Intermediate states of a simulation of a computational cell with three $\mathrm{C}$ planes in the $\mathrm{Al} / \mathrm{U}-7 \mathrm{wt} \% \mathrm{Mo}$ interface. $\mathrm{U}, \mathrm{Mo}, \mathrm{Al}$, and $\mathrm{C}$ atoms (and profiles) are denoted in blue, grey, yellow, and green, respectively. The original location of the interface (at the onset of the simulation) corresponds to the label " 0 ".

3.6.1. Zirconium as a Matrix. The simulations of Figure 11 show that the interface behavior at $T=800 \mathrm{~K}$ is quite different for the following two situations: Al/U-7 wt $\%$ Mo and $\mathrm{Zr} / \mathrm{U}-7 \mathrm{wt} \% \mathrm{Mo}$. The interface for $\mathrm{Zr} / \mathrm{U}-7 \mathrm{wt} \% \mathrm{Mo}$ is stable even at higher temperatures. The simulations clearly show a well defined U-Zr interface with a local ordering trend and also a Mo-free zone, smaller than in Si case. Our simulations show a strong $\mathrm{Al}$ migration to the $\mathrm{U}-\mathrm{Mo}$ side of the $\mathrm{Al} / \mathrm{U}-7 \mathrm{wt} \%$ Mo interface, as can be seen in the $\mathrm{Al}$ concentration profiles. It can be seen that there is enhanced $\mathrm{Al}$ content in the interaction-layer zone of the profile, as well as substantial presence of $\mathrm{Al}$ in the $\mathrm{U}-\mathrm{Mo}$ side of the computational cell. These results are both in agreement with the findings of Yunming et al. [35]. An exact match is clearly unrealistic due to the limitations in the calculations, such as the absence of structural and/or thermal vacancies, as well as the simplified description of the multicomponent system as prescribed by the BFS method.

Figure 12 compares the interface behavior at $T=550 \mathrm{~K}$ in the following three alternatives: (a) Al-5 wt $\% \mathrm{Si} / \mathrm{U}-7 \mathrm{wt} \%$ Mo, (b) Zr/U-7 wt\% Mo, and (c) Zr/U-10 wt\% Zr. The simulations show a clear interface and an almost unmodified matrix or fuel zone out of a reduced interaction zone in the last two cases. The results show that the interface with $\mathrm{Zr}$ remains unaltered almost up to $T=1000 \mathrm{~K}$ whereas if $\mathrm{Al}$ is used as a matrix the interface damage is important above $T=800 \mathrm{~K}$ (mainly due to $\mathrm{Al}$ and $\mathrm{U}$ interdiffusion). Above this temperature the energy barrier is broken and $\mathrm{Al}$ atoms diffuse deeply into the fuel. A recent experiment confirmed the improved behavior of the $\mathrm{Zr} / \mathrm{U}-7 \mathrm{wt} \%$ Mo fuel under irradiation [34].

3.6.2. The Role of $C$ in the Interface $A l / U-M o$. One expectation when using additives in the $\mathrm{Al}$ matrix is that the added element (or elements) will form weak bonds with $\mathrm{Al}$ and display a tendency towards compound formation with $\mathrm{U}$ and Mo. The opposite would be expected with elements added to the fuel. Ultimately, the goal is to diminish the interface-growing kinetics and perhaps avoid porosity and the formation of unwanted compounds. There is one other alternative to the use of additives, namely, coating the fuel particles with one or more elements or compounds with the aim of generating diffusional barriers in the interaction zone. This is yet one more case in which the lack of experimental results or any other guiding evidence motivates the use of modeling in order to preview qualitative changes before proceeding to experimental verification. We will show in this work that a single element fulfills all the required conditions. 


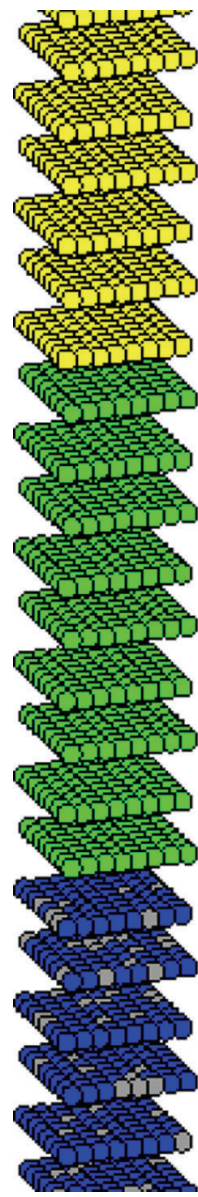

Original cell

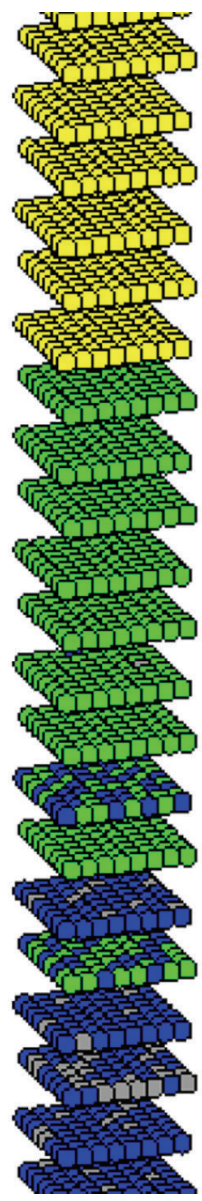

$T=120 \mathrm{~K}$

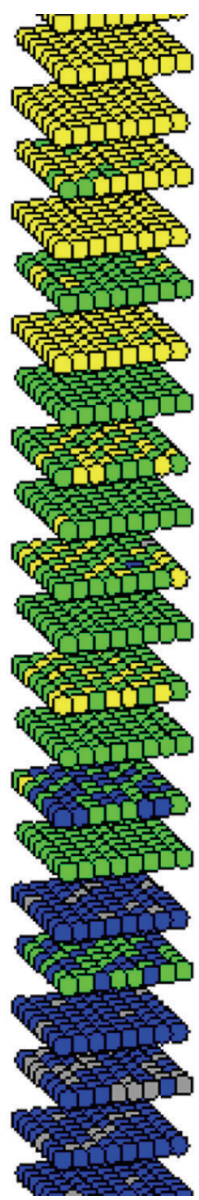

$T=300 \mathrm{~K}$
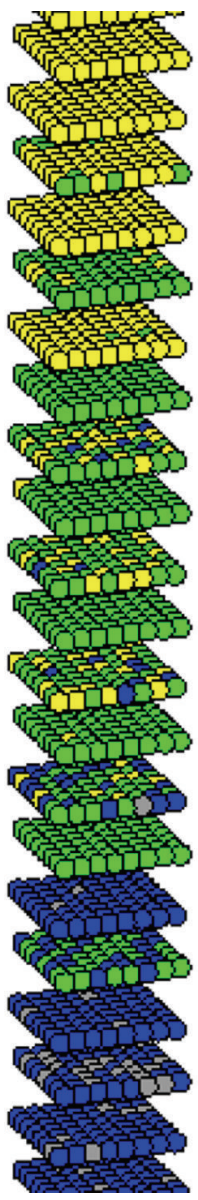

$T=600 \mathrm{~K}$
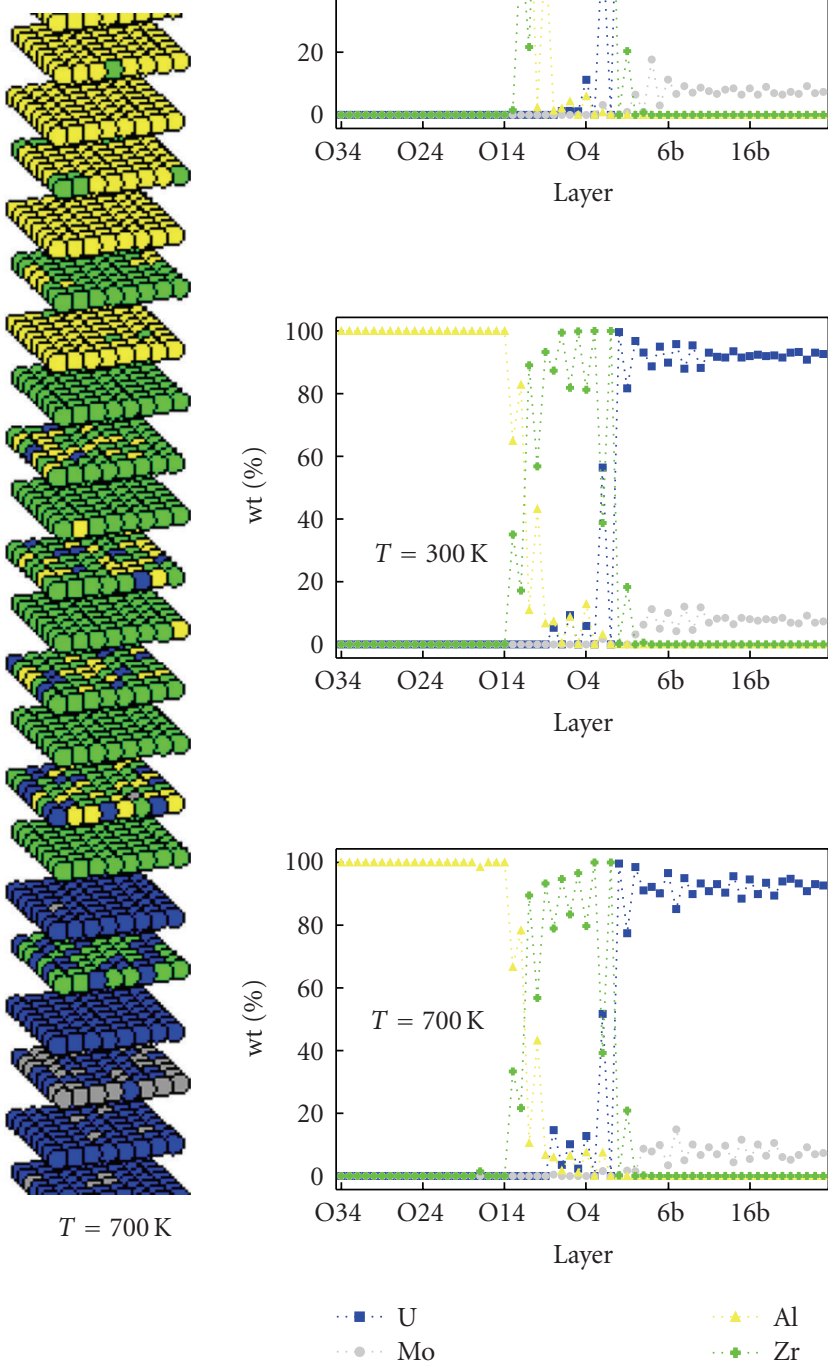

(b)

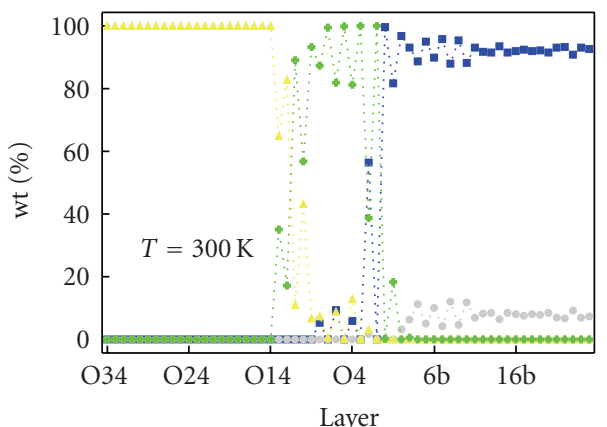

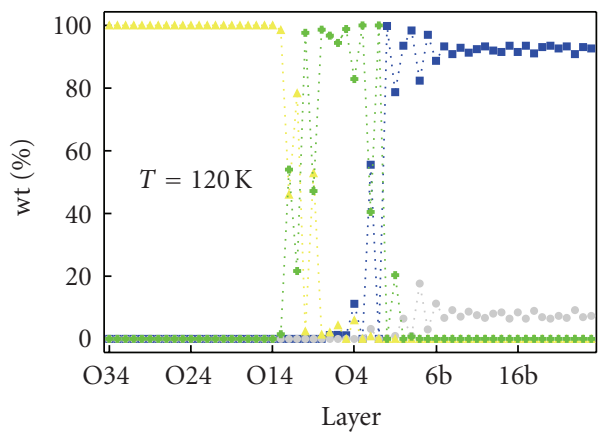

(a)

Figure 14: Intermediate states of a simulation of a computational cell with nine $\mathrm{C}$ planes in the $\mathrm{Al} / \mathrm{U}-7 \mathrm{wt} \% \mathrm{Mo}$ interface. $\mathrm{U}$, Mo, $\mathrm{Al}$, and $\mathrm{C}$ atoms (and profiles) are denoted in blue, grey, yellow, and green, respectively. The original location of the interface (at the onset of the simulation) corresponds to the label " 0 ".

Although there are no current alternatives to the use of $\mathrm{Si}$ in the experimental research, our modeling work proposed the use of $\mathrm{C}$ coating as a more effective diffusional barrier several years ago [25]. The atom-by-atom analysis shows that $\mathrm{C}$ controls the behavior of the other elements in the interface due to the stable compound formed with $\mathrm{Al}$ and $\mathrm{U}$. Figures 13 and 14 show the simulation results with three and nine C planes coating, respectively. Comparison of both figures suggests that the U-C local ordering plays the dominant role as an energy barrier for $\mathrm{Al}, \mathrm{U}$, and Mo atoms. The excess $\mathrm{C}$ reacts with $\mathrm{Al}$ to form (probably) an $\mathrm{Al}_{4} \mathrm{C}_{5}$ compound, thus resulting into a wider interface. The simulations also show that these compounds are formed at low temperature and low $\mathrm{C}$ deposition.

The high stopping power of the $\mathrm{C}$ coating raises a question on the comparative behavior and role between $\mathrm{Si}$ and $\mathrm{C}$ atoms in the $\mathrm{Al} / \mathrm{U}-\mathrm{Mo}$ interface. This modeling implies a five-element simulation, a task easily achievable within the atomistic modeling framework applied in this work. The most noticeable result in this work can be seen in Figure 15, where a three-plane $\mathrm{C}$ coating was deposited in the Al-5 wt $\%$ Si $/ U-7$ wt $\%$ Mo interface. The simulations clearly 


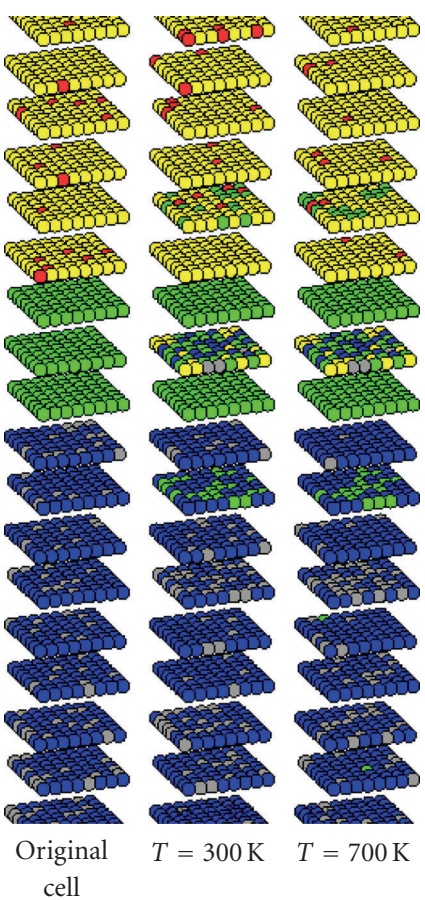

(a)
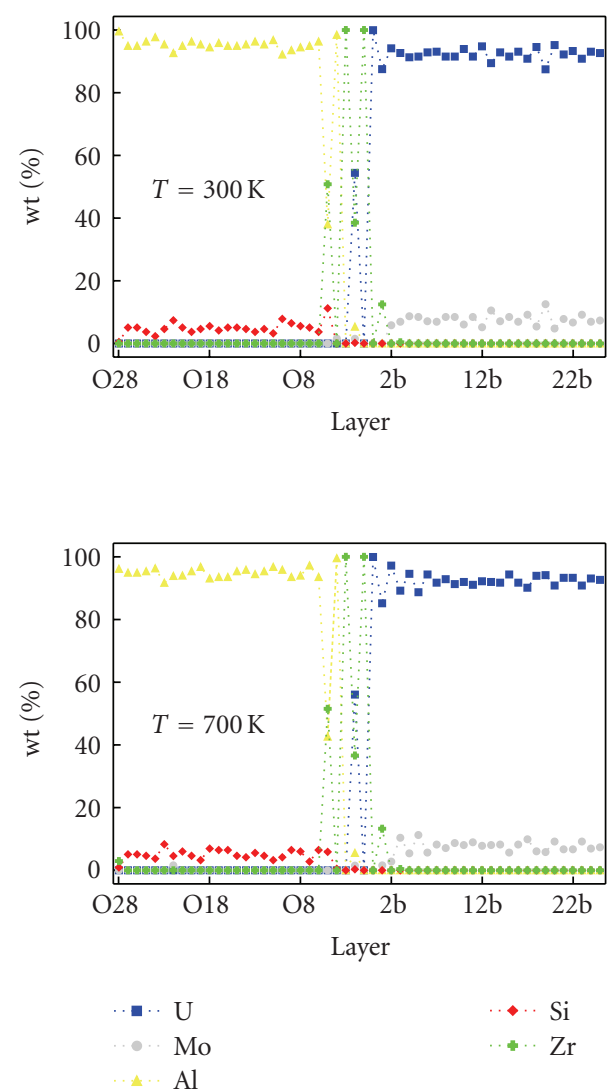

(b)

FIGURE 15: Intermediate states of a simulation of a computational cell with three C planes in the Al-5 wt $\%$ Si/U-7 wt $\%$ Mo interface. U, Mo, $\mathrm{Al}, \mathrm{Si}$, and $\mathrm{C}$ atoms (and profiles) are denoted in blue, grey, yellow, red, and green, respectively. The original location of the interface (at the onset of the simulation) corresponds to the label " 0 ".

show that the local ordering trend between $\mathrm{Al}-\mathrm{C}$ and $\mathrm{U}-\mathrm{C}$ elements inhibits $\mathrm{Si}, \mathrm{Mo}$, or $\mathrm{Al}$ diffusion, a clear difference with the behavior of the Al-Si/U-Mo interface.

The simulations also show a very well-defined interaction zone below $T=800 \mathrm{~K}$, a result that clearly arises from the change of role between $\mathrm{C}$ and Si. However, the high-quality diffusional barrier generated by the $\mathrm{C}$ coating is effective only for a minimum amount of three planes of $\mathrm{C}$, as can be seen in Figure 15. If only one plane of $\mathrm{C}$ is deposited, modeling shows that the interaction products formed are ineffective in stopping $\mathrm{Al}$ diffusion at a temperature as low as $T=500 \mathrm{~K}$.

Although the theoretical results suggest that $\mathrm{C}$ is a better alternative than Si to fix the technological problem in the development of high-density uranium fuels, they should be validated by experimental work. As no experimental results or guiding evidence are available for the system $\mathrm{Al}-\mathrm{Si} / \mathrm{C} / \mathrm{U}$ Mo, this is a good example of how computational modeling could help in the understanding of the behavior of the system before proceeding to experimental verification.

\section{Conclusions}

In this work, we applied the BFS method for alloys to model multicomponent systems and showed that atomistic computational modeling could become a valuable tool to aid the experimental work in the development of nuclear fuels through the understanding of the basic features observed in the $\mathrm{Al} / \mathrm{U}-\mathrm{Mo}$ interface, the effect of additives to the $\mathrm{Al}$ matrix such as in $\mathrm{Si}$ and $\mathrm{C}$, and the use of $\mathrm{Zr}$ as an alternative to $\mathrm{Al}$ matrix.

Although all the calculations were done in a rigid environment, where both the Al matrix and U-Mo particles are represented by a bcc lattice characteristic of the U-Mo fuel, the basic features characterizing the real system Al-Si/UMo can be identified. These include (1) the formation of interfacial compounds, (2) much reduced diffusion of $\mathrm{Al}$ into U-Mo due to the high Si concentration, (3) Si depletion in the $\mathrm{Al}$ matrix, and (4) an unexpected interaction between Mo and Si which inhibits the Si diffusion to deeper layers of the U-Mo solid solution and improves the stopping power for $\mathrm{Al}$ diffusion. Also, recent experimental results confirmed and supported early theoretical results as it is the minimum Si amount needed to generate an effective diffusional barrier, or the use of Zircaloy instead of Al-Si as matrix element. In addition, the use of $\mathrm{C}$ as an alternative to $\mathrm{Si}$ as a stabilizing element was also proposed. The use of $\mathrm{C}$ coating has several advantages compared to $\mathrm{Si}$, an element not desirable from a fuel reprocessing viewpoint, and allows incorporation in the fuel in a similar way as the currently developed Si. 
The nature of the results presented here suggests that modeling has reached the point where effective and practical answers can be obtained, solving or proposing solutions to current relevant problems. By becoming an integral and timely part of the decision process leading to further experimental work, it has the potential of streamlining this costly process with pointed answers to complex problems.

\section{Acknowledgments}

Fruitful discussions with N. Bozzolo are gratefully acknowledged. G. Bozzolo acknowledges financial support by the US Department of Energy Contract DE-AC02-06CH11357.

\section{References}

[1] M. K. Meyer, G. L. Hofman, S. L. Hayes et al., "Lowtemperature irradiation behavior of uranium-molybdenum alloy dispersion fuel," Journal of Nuclear Materials, vol. 304, no. 2-3, pp. 221-236, 2002.

[2] D. B. Lee, K. H. Kim, and C. K. Kim, "Thermal compatibility studies of unirradiated U-Mo alloys dispersed in aluminum," Journal of Nuclear Materials, vol. 250, no. 1, pp. 79-82, 1997.

[3] K. H. Kim, J. M. Park, C. K. Kim, G. L. Hofman, and M. K. Meyer, "Irradiation behavior of atomized U-10 wt\% Mo alloy aluminum matrix dispersion fuel meat at low temperature," Nuclear Engineering and Design, vol. 211, no. 2-3, pp. 229-235, 2002.

[4] G. L. Hofman, M. R. Finlay, and Y. S. Kim, "Recent observations at the postirradiation examination of low-enriched UMo miniplates irradiated to high burnup," in Proceedings of the 26th International Meeting on Reduced Enrichment for Research and Test Reactors (RERTR '04), Vienna, Austria, 2004.

[5] A. Leenaers, S. Van den Berghe, and E. Koonen, "Postirradiation examination of uranium-7wt\% molybdenum atomised dispersion fuel," in Proceedings of the 8th International Topical Meeting on Research Reactor Fuel Management (RRFM '04), Munich, Germany, 2004.

[6] A. Leenaers, S. Van Den Berghe, E. Koonen et al., "Postirradiation examination of uranium-7 $\mathrm{wt} \%$ molybdenum atomized dispersion fuel," Journal of Nuclear Materials, vol. 335, no. 1, pp. 39-47, 2004.

[7] S. Van den Berghe, W. Van Renterghem, and A. Leenaers, "Transmission electron microscopy investigation of irradiated U-7 wt\% Mo dispersion fuel," Journal of Nuclear Materials, vol. 375, no. 3, pp. 340-346, 2008.

[8] S. Van den Berghe, W. Van Renterghem, and A. Leenaers, "Transmission electron microscopy investigation of irradiated U-7 wt\% Mo dispersion fuel," in Proceedings of the 29th International Meeting on Reduced Enrichment for Research and Test Reactors (RERTR '07), Prague, Czech Republic, 2007.

[9] J. Gan, D. D. Keiser Jr., D. M. Wachs, A. B. Robinson, B. D. Miller, and T. R. Allen, "Transmission electron microscopy characterization of irradiated U-7Mo/Al-2Si dispersion fuel," Journal of Nuclear Materials, vol. 396, no. 2-3, pp. 234-239, 2010.

[10] J. Gan, D. Keiser, D. Wachs et al., "Microstructure of RERTR DU-Alloys Irradiated with Krypton Ions," in Proceedings of the 31th International Meeting on Reduced Enrichment for Research and Test Reactors (RERTR '09), Beijing, China, 2009.
[11] G. L. Hofman, Y. S. Kim, H. J. Ryu et al., "Attempt to solve the instability in the irradiation behaviour of low enriched UMo-Al dispersion fuel," in Proceedings of the 10th International Topical Meeting on Research Reactor Fuel Management (RRFM '06), Sofia, Bulgaria, 2006.

[12] Y. S. Kim, G. L. Hofman, P. G. Medvedev, G. V. Shevlyakov, A. B. Robinson, and H. J. Ryu, " Post irradiation analysis and performance modeling of dispersion and monolithic U-Mo fuels," in Proceedings of the 29th International Meeting on Reduced Enrichment for Research and Test Reactors (RERTR '07), 2007.

[13] A. Leenaers, S. Van den Berghe, F. Charollais et al., "Microstructural analysis of ground UMo fuel with and without $\mathrm{Si}$ added to the matrix, irradiated to high burn up," in Proceedings of the 31th International Meeting on Reduced Enrichment For Research And Test Reactors (RERTR '09), Beijing, China, 2009.

[14] Y. S. Kim, G. Hofman, and A. B. Robinson, "Effect of Si additions in $\mathrm{Al}$ in $\mathrm{U}-\mathrm{Mo} / \mathrm{Al}$ dispersion plates: Observations from side-by-side plates irradiated in RERTR-6, -7A, -9A and -9B," in Proceedings of the International Topical Meeting on Research Reactor Fuel Management (RRFM 09), Vienna, Austria, 2009.

[15] A. Leenaers, S. Van den Berghe, S. Dubois, J. Noirot, M. Ripert, and P. Lemoine, "Microstructural analysis of irradiated atomized $\mathrm{U}(\mathrm{Mo})$ dispersion fuel in an $\mathrm{Al}$ matrix with $\mathrm{Si}$ addition," in Proceedings of the International Topical Meeting on Research Reactor Fuel Management (RRFM '08), Hamburg, Germany, 2008.

[16] A. Leenaers, S. Van den Berghe, M. Ripert et al., "Irradiation Behavior of Atomized and Ground U(Mo) Dispersion Fuel," in Proceedings of the 30th International Meeting on Reduced Enrichment for Research and Test Reactors (RERTR '08), Washington, DC, USA, 2008.

[17] D. D. Keiser, A. B. Robinson, J. F. Jue, P. Medvedev, D. M. Wachs, and M. R. Finlay, "Microstructural development in irradiated U-7Mo/6061 Al alloy matrix dispersion fuel," Journal of Nuclear Materials, vol. 393, no. 2, pp. 311-320, 2009.

[18] G. Hofman, Y. S. Kim, and A. B. Robinson, "Method of Utilizing the Stabilizing Effect of Silicon in U-Mo-Al Dispersion Fuel and Minimum Si Addition Required for Given Operating Conditions," in Proceedings of the 31th International Meeting on Reduced Enrichment For Research and Test Reactors (RERTR '09), Beijing, China, 2009.

[19] S. Van den Berghe, A. Leenaers, and C. Detavernier, "SELENIUM fuel: Surface engineering of U(Mo) particles to optimize fuel performance," in Proceedings of the International Topical Meeting on Research Reactor Fuel Management (RRFM '10), Morocco, Marrakech, 2010.

[20] J. E. Garcés, G. Bozzolo, G. Hofman, and J. Rest, "Modeling of multicomponent systems: Role of $\mathrm{Mo}$ and $\mathrm{Si}$ on the interaction of $\mathrm{Al}$ and $\gamma$-UMo," Computational Materials Science, vol. 40, no. 1, pp. 6-19, 2007.

[21] J. E. Garcés, G. Bozzolo, G. Hofman, and J. Rest, "Role of Si on the $\mathrm{Al}$ behavior in the reaction layer of AlUMo diffusion couples," Applied Physics Letters, vol. 90, no. 7, Article ID 074104, 3 pages, 2007.

[22] J. Garcés, G. Bozzolo, J. Morse, J. Rest, and G. Hofman, "Modeling of low enrichment uranium fuels for research and rest reactors," in Applied Computational Materials Modeling: Theory, Experiment and Simulation, G. Bozzolo, P. Abel, and R. Noebe, Eds., chapter 14, pp. 451-483, Springer, New York, NY, USA, 2007. 
[23] J. Garcés and G. Bozzolo, "Computational Modeling of Materials," in Proceedings of the Autumn Meeting on High Density Uranium Fuels, Constituyentes Atomic Center, CNEA, Buenos Aires, Argentina, 2004.

[24] J. Garcés and G. Bozzolo, "Effect of Si, Mg and Os on the $\mathrm{Al} / \mathrm{U}-\mathrm{Mo}$ interface," in Proceedings of the Spring Meeting on High Density Uranium Fuels, Computational Modeling of High Sensity Uranium Fuels, Constituyentes Atomic Center, CNEA, Buenos Aires, Argentina, 2004.

[25] J. Garcés and G. Bozzolo, "Effect of Ge and C on the Al/U-Mo interface," in Proceedings of the Spring Meeting on High Density Uranium Fuels, Computational Modeling of High Density Uranium Fuels, Constituyentes Atomic Center, CNEA, Buenos Aires, Argentina, 2005.

[26] G. Bozzolo, J. Ferrante, and J. R. Smith, "Method for calculating alloy energetics," Physical Review B, vol. 45, no. 1, pp. 493-496, 1992.

[27] J. R. Smith, T. Perry, A. Banerjea, J. Ferrante, and G. Bozzolo, "Equivalent-crystal theory of metal and semiconductor surfaces and defects," Physical Review B, vol. 44, no. 12, pp. 6444-6445, 1991.

[28] J. E. Garcés and G. Bozzolo, "Determination of structural alloy equilibrium properties from quantum approximate methods," Physical Review B, vol. 71, no. 13, Article ID 134201, pp. 1-10, 2005.

[29] P. Blaha, P. K. Schwarz, G. K. H. Madsen, D. Kvasnicka, and J. Luitz, WIEN2K, an Augmented Plane Wave+Local Orbital Program for Calculating Crystal Properties, Technische Universität Wien, Austria, 2001.

[30] M. Mirandou, M. Granovsky, M. Ortz, S. Balart, S. Aricó, and L. Gribaudo, "Reaction layer between u-7wt\% mo and al alloys in chemical diffusion couples," in Proceedings of the 26th International Meeting on Reduced Enrichment for Research and Test Reactors (RERTR '04), Vienna, Austria, 2004.

[31] G. Bozzolo and J. Garcés, "Surface Alloys and Alloy Surfaces," in The Chemical Physics of Solid Surfaces, D. P. Woodruff, Ed., vol. 10, p. 30, Elsevier, New York, NY, USA, 2002.

[32] J. P. Perdew, K. Burke, and M. Ernzerhof, "Generalized gradient approximation made simple," Physical Review Letters, vol. 77, no. 18, pp. 3865-3868, 1996.

[33] J. Garcés, G. Hofman, M. K. Meyer, E. E. Pasqualini, J. L. Snelgrove, and H. Taboada, in Proceedings of the Meeting held in Constituyentes Atomic Center, CNEA, Buenos Aires, Argentina, 2004, Private communication.

[34] E. E. Pasqualini, "Advances and perspectives in u-mo monolithic and dispersed fuels," in Proceedings of the International Meeting on Reduced Enrichment for Research and Test Reactors (RERTR '06), Cape Town, South Africa, 2006.

[35] L. Yunming, Y. Changgeng, S. Changlong, and C. Jiangang, in Proceedings of the 31th International Meeting on Reduced Enrichment for Research and Test Reactors (RERTR), Beijing, China, 2009. 

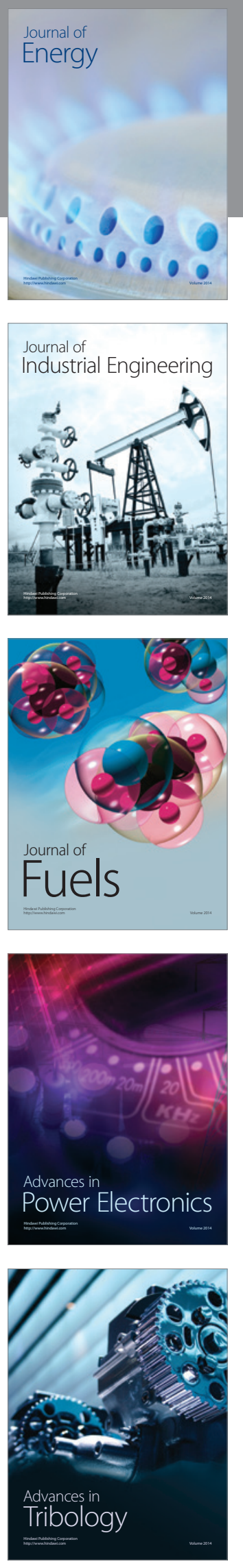
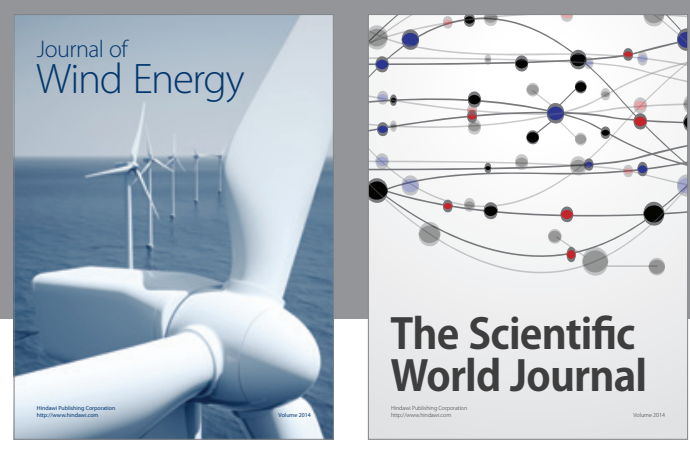

The Scientific World Journal

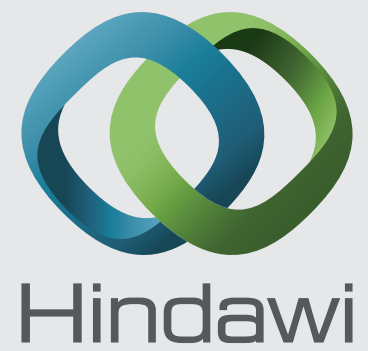

Submit your manuscripts at http://www.hindawi.com
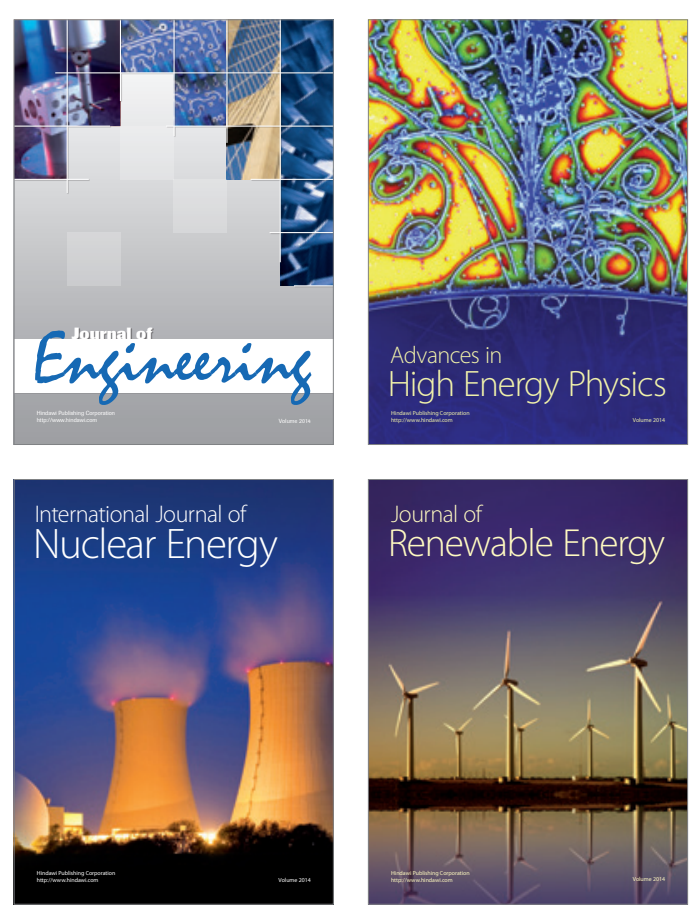

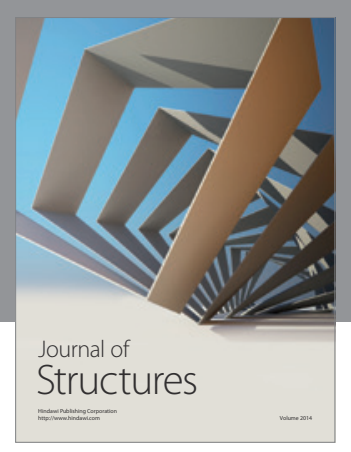

Rotating
Mechinery
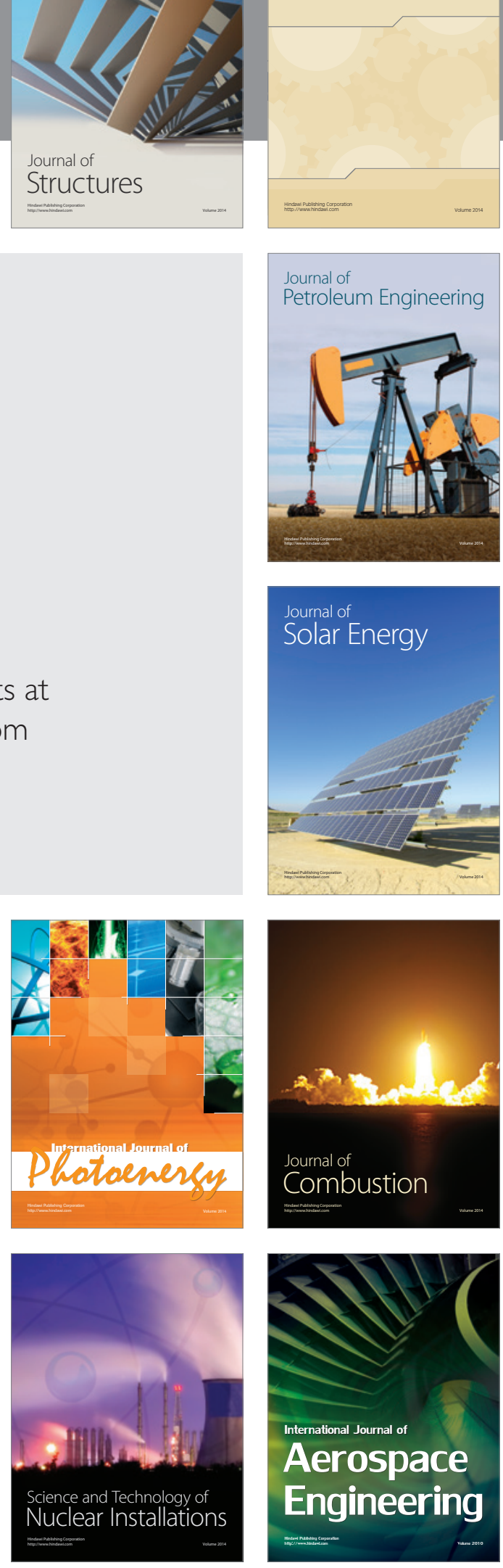